Portland State University

PDXScholar

\title{
A Study of Shame-proneness, Drinking Behaviors, and Workplace Role Ambiguity Among a Sample of Student Workers
}

Sarah Nielsen Haverly

Portland State University

Follow this and additional works at: https://pdxscholar.library.pdx.edu/open_access_etds

Part of the Psychology Commons

Let us know how access to this document benefits you.

\section{Recommended Citation}

Haverly, Sarah Nielsen, "A Study of Shame-proneness, Drinking Behaviors, and Workplace Role Ambiguity Among a Sample of Student Workers" (2017). Dissertations and Theses. Paper 3508.

https://doi.org/10.15760/etd.5392

This Thesis is brought to you for free and open access. It has been accepted for inclusion in Dissertations and Theses by an authorized administrator of PDXScholar. Please contact us if we can make this document more accessible: pdxscholar@pdx.edu. 
A Study of Shame-proneness, Drinking Behaviors, and Workplace Role Ambiguity

Among a Sample of Student Workers

by

Sarah Nielsen Haverly

A thesis submitted in partial fulfillment of the requirements for the degree of

\author{
Master of Science \\ in \\ Psychology
}

Thesis Committee:

Cynthia Mohr, Chair

Todd Bodner

Leslie Hammer

Portland State University

2017 


\begin{abstract}
As many as $50 \%$ of full time students are employed for pay while enrolled in secondary education (Condition of Education; Planty et al., 2009). It is well documented that college is a vulnerable time for heavy drinking, and similarly, increased consumption among the workforce continues to rise. Student workers, who occupy both roles, therefore may be particularly at risk. The present research explored potential factors related to this stressful dual role experience, which was hypothesized be related to increased alcohol consumption. One such factor proposed was the self-conscious emotion of shame. According to Hull's (1981) Self Awareness Model, individuals may drink to decrease levels of self-awareness in light of real or perceived failure or intensely negative emotional experiences. Based on this theory, both state and trait shame (shameproneness) have been linked with alcohol consumption. In line with the literature, it was hypothesized that individuals higher in shame-proneness would report recent experiences of shame, as well higher levels of alcohol consumption. It was additionally proposed that this process might be exacerbated for individuals experiencing workplace role ambiguity. Role ambiguity obfuscates both the process necessary for achieving favorable work outcomes, as well as whether those outcomes are or are not actually achieved. Therefore, individuals experiencing high levels of role ambiguity may exist in a continuous experience of wondering if they are doing their jobs correctly or well. The relation between shame-proneness (a trait) and experiences of shame (a state) was proposed to be moderated by the experience of role ambiguity. The present study revealed, however, that there were no direct, indirect, or conditional effects. The discussion explores possible
\end{abstract}


reasons for these outcomes, and offers thoughts regarding future research directions for further exploring these questions.

Keywords: alcohol, shame, shame-proneness, role ambiguity, student workers 


\section{Acknowledgements}

I would like to thank my committee for their time, insights, and support of this thesis project. Thank you to the Portland State University Psychology Department. I would also like to thank my friends and family who supported me through this writing process, most particularly my husband, Kyle. 


\section{Table of Contents}

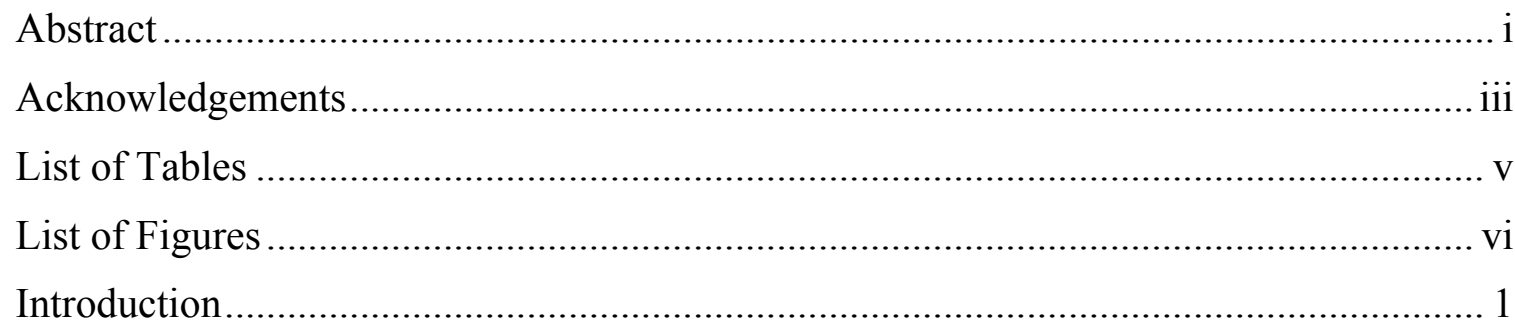

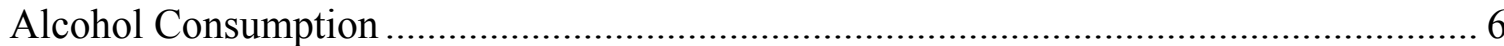

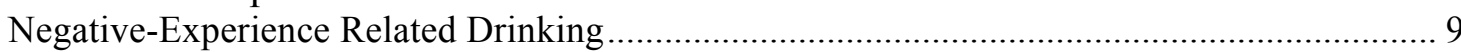

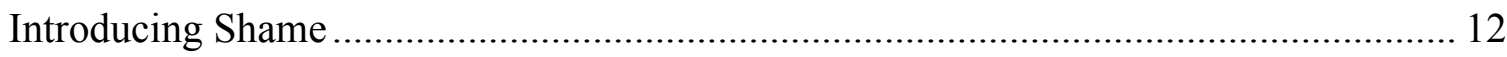

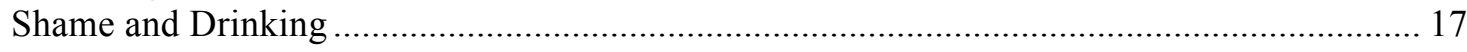

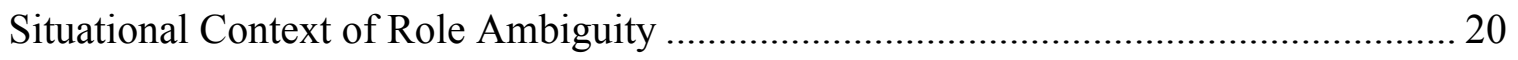

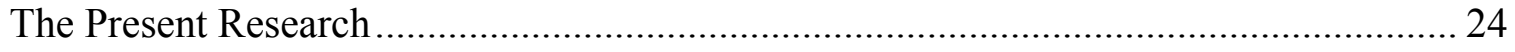

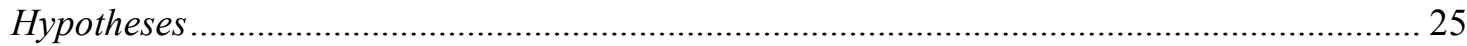

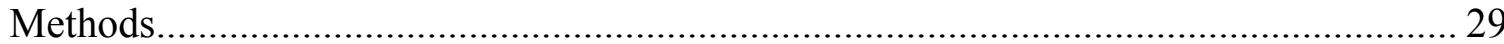

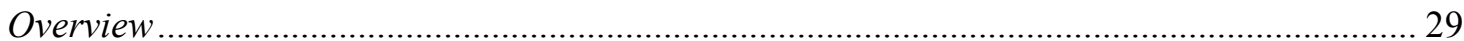

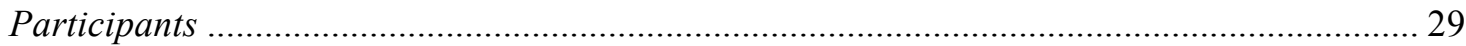

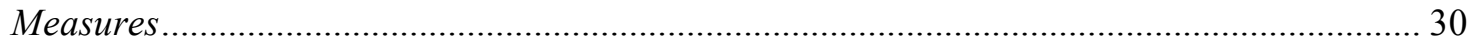

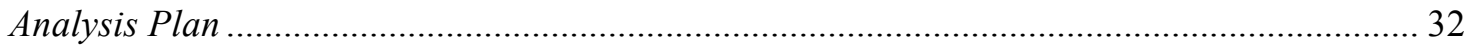

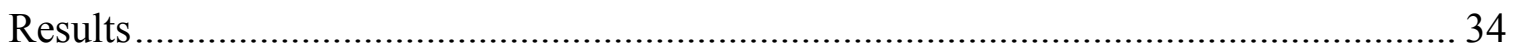

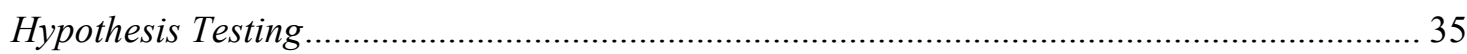

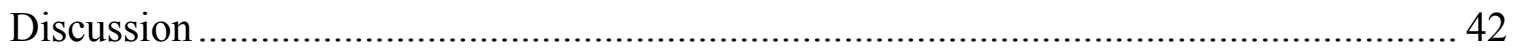

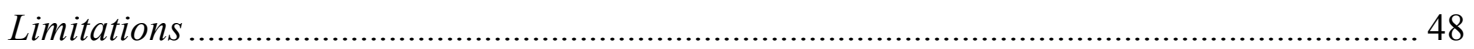

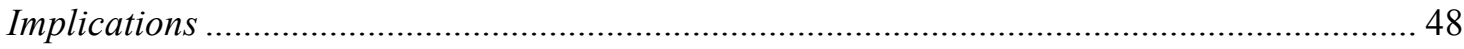

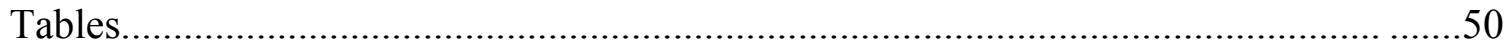

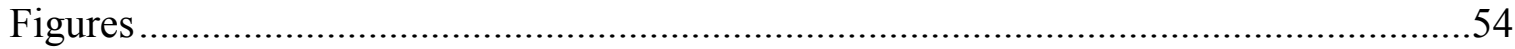

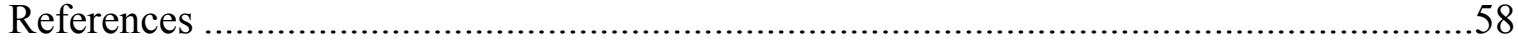

Appendix A: Guilt and Shame-Proneness Scale........................................................... 71

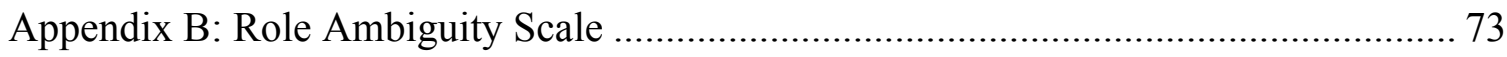




\section{List of Tables}

Table 1: Participant Demographics.........................................50

Table 2: Study Descriptive Statistics and Correlation Matrix .......................51

Table 3: Conditional Process Analyses for Drinking Frequency.......................52

Table 4: Conditional Process Analyses for Drinking Quantity........................53 


\section{List of Figures}

Figure 1: Conceptual Model...............................................54

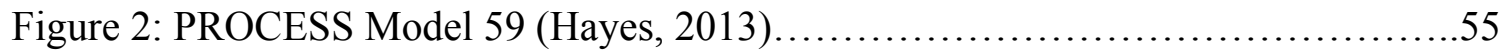

Figure 3: Interaction of role ambiguity and state shame on drinking frequency..........56

Figure 4: Interaction of role ambiguity and state shame on drinking quantity.............57 
SHAME-PRONENESS, DRINKING BEHAVIORS, AND ROLE AMBIGUITY

A study of shame-proneness, drinking behaviors, and workplace role ambiguity among a sample of student workers

\section{Introduction}

The last several years have marked greater attention to Total Worker Health. This growing research field emphasizes the promotion of workplace injury and illness prevention, as well as worker protection from workplace health and safety hazards. This approach to worker well-being also includes interventions on health behaviors that take place outside the workplace, such as exercise and general health (e.g., Proper, et al., 2003), and stress management (e.g.,Richardson \& Rothstein, 2008). As awareness and study of total worker health increase, so does our understanding of what is included for consideration. Alcohol consumption among the workforce, even outside of work, is demonstrated to have significant consequences for individuals, organizations, and society. Blum, Roman, and Martin (1995), for example, explore the health consequences of alcohol consumption on individual workers, while other researchers demonstrate that organizational level factors like productivity (e.g., Mullahy \& Sindelar, 1998), work performance (e.g., Ames, Grube, \& Moore, 1997), and safety behaviors (e.g., Frone, 2003) are negatively impacted by employee alcohol consumption. Above and beyond these consequences, it is evident in the literature that increased alcohol consumption increases health care costs, both for employees and employers alike. In fact, an economic analysis of data from the year 2006 (Bouchery et al., 2011) estimates that excessive alcohol consumption in the United States cost $\$ 223.5$ billion that year alone; these costs stemmed primarily from lost productivity $(72.2 \%)$, increased healthcare costs $(11 \%)$, and 
interaction with the criminal justice system (9.4\%). Of important note, however, is that these estimates of healthcare cost only include cost for specialty treatment for alcohol dependence, abuse, and other diagnoses specifically identified as alcohol related, suggesting that indirect costs are higher still.

However, one group of workers who may be at particular risk is those employees balancing multiple roles. Specifically, the present research investigates student workers, as the intersection between work strain and college norms around drinking may put this group at uniquely high risk. While extensive literature is devoted to investigating college students, and still more to workplace processes that may be present within the university experience (e.g., stress by Cotton, Dollard, \& De Jonge, 2002; burnout and engagement by Schaufeli, Martinez, Pinto, Salanova, \& Bakker, 2002), little is known about those students who are also balancing work responsibilities, particularly as it pertains to drinking behavior. As the cost of attending four-year colleges and universities continues to rise, students who work for pay outside of their role as students remain common, and will likely grow over time. In fact, according to the National Center for Education Statistics (Condition of Education, Planty et al., 2009), nearly 50\% of full time college students (age 16-24) were employed for pay outside of their role as students, with 10\% reporting employment commitments of 35 or more hours per week. According to the same report, over $80 \%$ of part-time enrolled students are employed. According to Hammer and colleagues (1998), student workers reported a relatively high degree of work-school role conflict. Since working students represent a population with multiple 
roles, responsibilities, and opportunities for strain, they present an important experience worthy of investigation.

One potential outcome of the stress experienced by these working students is excessive alcohol consumption. Indeed, college students consume large amounts of alcohol, which is of concern. In a groundbreaking investigation by Slutske and colleagues (2004) examining female twins, college students were revealed to consume significantly more alcohol than their non-college attending peers. This was even true among the $21 \%$ of the sample of twins that had mixed student status (that is, one twin attended college while the other did not). A more recent study also examined prevalence rates of drinking among a U.S. sample aged 18-29 where 30\% were currently enrolled as college students $(n=8,666)$. The findings demonstrate that binge drinking $(5+$ drinks per occasion for men, 4+ for women) was significantly more common in college students than in the general population sample. Additionally, rates of meeting diagnostic criteria for alcohol abuse and dependence was significantly higher in college students than among their nonstudent peers (Dawson, Grant, Stinson, \& Chou, 2005).

It is well documented that college is a highly normative time for heavy drinking (e.g., Chen \& Kandel, 1995). Additional research demonstrates that students highly endorse motivated drinking, specifically, drinking to cope with negative emotions (Park \& Levenson, 2002). Drinking to cope is demonstrated to be closely connected to the development of problematic drinking patterns over time, even at low levels of consumption (Cooper et al., 1995). Of particular concern is the role of drinking to cope, which is uniquely related to the development of alcohol problems. 
Considering this body of work, when paired with the evidence of stress-related drinking among workers, there is evidence for the particular importance of studying this group of student workers. In fact, as a group comprised of those who are high risk for increased consumption due to their student status, as well as those who are at increased risk through the strain of employment, this group may be doubly at risk. It is both important and necessary to strive to illuminate those mechanisms that contribute to problematic alcohol consumption among both students and workers, but most especially where the two groups intersect: student workers. By exploring and explaining mechanisms that contribute to problematic drinking behavior, research provides expanded opportunities for workplace or university interventions to improve the lives of workers and students.

Relying on this interesting and ever growing population, the present research explored some of the potential factors that may be related to increased alcohol consumption. Beginning with an exploration and definition of the problem of alcohol consumption among the workforce, I then suggested specific risk factors for further examination; including, the emotional trait of shame-proneness, and discrete (i.e., state) experience of shame, in their relation to alcohol consumption. In line with the literature, it was hypothesized that individuals higher in shame-proneness will report recent experiences of shame, as well as higher levels of alcohol consumption. It was proposed that greater shame-proneness, and experiences of shame, may account for higher alcohol consumption. Specifically, I suggested that recent experiences of shame would mediate the relationship between shame-proneness and alcohol use. While some research 
investigates the relation between shame and drinking, this investigation contributed to the literature by investigating a working population, as well as those individuals engaging in all levels of reported drinking (as opposed to only heavy and problematic drinkers [i.e., alcoholics] as previous literature has often done). This examination additionally contributed to the literature by investigating the link between shame-proneness and drinking within college student drinkers.

Additionally, I proposed that this process may be exacerbated for individuals experiencing workplace role ambiguity. That is, shame-proneness was more likely to lead to discrete experiences of shame within the context of increased role ambiguity, and the relation between shame-proneness (a trait) and experiences of shame (a state) were proposed to be moderated by the experience of role ambiguity. As will be described in more detail subsequently, role ambiguity obfuscates both the process necessary for achieving favorable work outcomes, as well as the determination of whether those outcomes are or are not actually achieved. Therefore, individuals experiencing high levels of role ambiguity may exist in a continuous experience of wondering if they are doing their jobs correctly or well. I proposed that this ambiguity may uniquely contribute to recent experiences of shame for shame-prone individuals. Along side these suggestions, I investigated the research question of whether or not role ambiguity might impact the relationship between recent experiences of shame and increased drinking.

Ultimately the goal of this thesis was to examine and illustrate contributing factors to increase alcohol consumption. Perhaps by illustrating some of these mechanisms, this research might be used to develop more primary intervention 
mechanisms. As is amply described in the literature, alcohol involvement is a large, and ever growing issue in the United States. Additionally, the present research may have implications that can offer insight into workplace factors, under the control of organizations and supervisors that can contribute to employee drinking for some employees. Thus, this line of research may elucidate an organizational opportunity for change that may reduce hazardous drinking for employees.

\section{Alcohol Consumption}

The National Institute on Alcohol Abuse and Alcoholism (NIAAA, 2004) defines problematic drinking as greater than two drinks per day for men and one drink per day for women. While alcohol consumption at this level is certainly problematic, more and more research suggests that even moderate-to-heavy drinking, the level at which problems may begin to appear but are not yet diagnosable, can have negative consequences for individuals and workplaces.

According to the Center for Disease Control (2014), excessive drinking is associated with increased health problems including, but not limited to, chronic diseases, several types of cancer, high blood pressure, pancreatitis, and alcohol poisoning. Additionally, several other concerns like social problems, learning and memory problems, mental health issues like anxiety and depression, and alcohol dependence and abuse may result from excessive drinking (CDC, 2014). In addition to this myriad of health-related issues, previous research also demonstrates that drinking can cause problems for members of the workforce, uniquely. Mangione and colleagues (1999) report that heavy drinkers in particular report greater work-related issues (e.g., 
absenteeism, interpersonal conflict with coworkers, lower productivity, and lower quality of work) than do their lesser drinking counterparts. Considering more recent research, which points to the high rates of drinking within the American workforce, these findings are particularly problematic.

In 2008, Frone reported prevalence rates of American workforce alcohol consumption. Seventy four percent of workers consumed alcohol within the most recent 12 months, with $31 \%$ reporting drinking to intoxication at some point during that time. Additionally, 23\% reported experiencing next-day hangovers from alcohol consumption (Frone, 2008). Later Frone (2015) indicated that among the U.S. workforce 12-month prevalence rates, $26 \%$ or drinkers reported heavy drinking (i.e., greater than or equal to 5 drinks per day). Furthermore, the same study found that among drinkers, 38\% initiated alcohol use within two hours of leaving work, with $6 \%$ of those individuals consuming four or more drinks (i.e., binging) in that sitting following the workday. Research among the highly educated workforce (i.e., bachelors degree or higher) reveals even stronger findings. Matano and colleagues (2002) found in a community adult sample $(\mathrm{n}=504)$, among whom over $80 \%$ held bachelors degrees or higher, $87 \%$ reported alcohol consumption within the past year; $13 \%$ of respondents reported consuming three or more drinks daily, and $12 \%$ of the sample was assessed as having a high likelihood of lifetime alcohol dependence based on scores on the Alcohol Use Disorders Identification Test (AUDIT; Babor et al., 1989; Conigrave, Hall, \& Saunders, 1995). The authors note that $93 \%$ of this sample held administrative, managerial, or professional jobs. 
While high alcohol consumption alone is a considerable issue, it is of even greater concern when considering the many problematic consequences of the behavior. In addition to the health concerns already enumerated, there are many significant workplace outcomes of alcohol use. These issues include interpersonal problems like conflict with coworkers (Mangione et al., 1999) and conflict with supervisors (Ames et al., 1997). Increased alcohol consumption among workers is also found to contribute to decreased productivity by reducing performance on tasks requiring attention and effort (Holloway, 1994), increasing absenteeism (Cunradi, Griener, Ragland, \& Fisher, 2005), and general performance issues like self-reported low-performance and falling asleep at work (Ames et al., 1997). Considering all of these issues and potential problems as one, it becomes clear and essential to gain better understanding of the predictors of alcohol use among the workforce.

There are certainly many reasons that alcohol consumption is prevalent among the American workforce. One reason in particular, which is supported both intuitively and empirically, is to relieve negative experiences, such as work-related stress and tension. The literature refers to this concept as motivated drinking, which is to say that alcohol consumption is spurred by an individual's expectations of alcohol consumption experiences. Theory and empirical evidence alike support that an individual's desire to regulate affective experience is one of the important motivating factors that underlie alcohol use. In fact, Wills and Shiffman (1985) report that individuals use alcohol to enhance positive feelings when feeling under stimulated or tired, as well as to reduce negative emotions while anxious or over aroused. Motivated drinking specific to 
negative experiences is of particular importance for the present research, and may be of special concern to those individuals with competing demands on their time (e.g., student workers).

Negative-Experience Related Drinking

One theory describing negative experience-related drinking is the Tension Reduction Hypothesis (TRH), which is commonly relied upon when studying drinking among working populations because it asserts that people drink alcohol, in part, because it reduces tension. This hypothesis developed out of Conger's 1956 theory regarding alcohol's reinforcement properties, and contains two essential propositions: First, that alcohol consumption will reduce tension under many circumstances; and second, that while experiencing tension, people will be particularly motivated to consume alcohol. Some work supports the theory's assertion that alcohol consumption may stave off the psychological and physiological experiences of stress (e.g., Sher, Bartholow, Peuser, Ericson, \& Wood, 2007). This response is exacerbated over time, in part, due to this successful stress-dampening response, which reinforces the use of alcohol to the same ends over time. These responses are a direct result of a behavioral reinforcement feedback loop: Individuals, for a variety of reasons, drink when they have negative experiences or feelings (i.e., tension), that drinking reduces the tension, which in turn reinforces drinking in similar stressful situations in the future. This cycle can lead to more abusive and problematic drinking over time, as it also reduces an individual's capacity to cope adaptively with stressors (Maisto, Carrey, \& Bradizza, 1999). The 
present research relies on this literature to focus on the second component of the cycle, stipulating that people will drink while experiencing negative emotions.

The assumption that people drink when experiencing negative emotions is widely held (Greeley \& Oei, 1999). We see this evidence in common colloquialisms like "crying in your beer" or "taking the edge off." In the past, correlational studies test the TRH, and examine the relationship between stressful events and alcohol consumption. However, these studies produce mixed results at best, and often underestimate or ignore the importance of interpersonal factors (West \& Sutker, 1990). While these relationships between stress and alcohol consumption seem intuitive, support is sometimes mixed in the literature, especially when researchers do not properly account for contextual and individual factors. Experts have called for more thorough investigation of the types of stressor experiences that may influence alcohol involvement (Frone, 1999; Sayette, 2000).

There are certainly many different experiences that are potentially associated with drinking, however, interpersonal experiences are argued to be of critical importance (e.g., Mohr et al., 2001). However, closely related to interpersonal experiences are social emotions, that is, those emotional experiences that are related to the mental states of other people. Basic emotions (like happiness and sadness) are not dependent on others, while social emotions like embarrassment, guilt, pride, empathy, and shame are (Burnett, Bird, Moll, Frith, \& Blackemore, 2009). Negative interpersonal experiences, and related negative social emotions, are among the most frequently reported, as well as some of the most averse stressors (Bolger, DeLongis, Kessler, \& Schilling, 1989). Expectedly, much 
research has demonstrated interpersonal factors as a key risk factor for increased drinking. In a seminal work by Cox and Klinger (1988), the authors explore motivational models for drinking. A key element of these motives, the authors posit, is the incentive presented, which, in the case of alcohol are often interpersonal. Both positive interpersonal incentives can come from drinking, as well as the avoidance of negative incentives. This motivational model offered a starting point for the influential work of Cooper and colleagues. Cooper's work illustrates even more extensively how interpersonal relationships impact drinking motivations and behaviors. For example, Cooper (1994) reports that adolescent drinker experience substantial motivation to drink due to the desire to conform to others.

An alternative model to the TRH describes more specific instances of negative experience-related drinking; namely the Self-Awareness Model of Alcohol Consumption (Hull, 1981). Hull suggests that above and beyond simply drinking to reduce general tension, individuals may drink to decrease levels of self-awareness. This model states that alcohol decreases self-awareness by interfering with the cognitive encoding process (e.g., Hull, Levenson, \& Young, 1983; Carver \& Scheier, 1978; Davis \& Brock, 1975). Hull goes on to suggest that, "alcohol effectively interferes with higher order mental processes involved in self-aware states and thereby reduces the individual's sensitivity to information regarding the self' (Hull, 1981, p. 588). Hull specifically mentions that one such type of information may be the negative implications of failure, and that subsequently, alcohol use is associated with decreased responsiveness to such negative feedback. 
One of the specific affective experiences related to self-awareness is that of shame. Shame is considered a self-conscious emotion, that is, a feeling we have about the self. Prominent research suggests that self-conscious emotions (e.g., shame, guilt, embarrassment) may, in fact, be uniquely powerful among affective experiences, specifically because they are related to and reliant on the self (Tangney \& Fischer, 1995). Additionally, shame has been empirically linked to alcohol consumption via the selfawareness model (Mohr, Brannan, Mohr, Armeli, \& Tennen, 2008; Mohr, Armeli, Tennen, \& Todd, 2010) and may play a role in drinking among student workers.

\section{Introducing Shame}

Shame is a universal and powerful emotion. The experience can play a role in motivation, thought regulation, feelings, and behaviors (Fischer, \& Tangney, 1995). Notably defined by Lewis (1971), shame involves a global negative feeling about the self in response to a [perceived] misdeed or shortcoming. It is important to understand that shame, an internal emotional experience, is preceded by an external experience that gives rise to shame. However, contrary to popular believe, there is no empirical support of "classic" or universal shame-inducing situations (Tangney, 1992). In fact, many events predictably precede guilt and shame equally (e.g., cheating, stealing, lying, failing to help another, etc.), but the difference in experience appears to lie in the shame or guilt proneness of the individual (Tangney, 1996). Shame-proneness and shame are distinct constructs, however (Tangney, 1995). Shame-proneness is a trait, referring to an individual's propensity to experience the painful emotion of shame (Tangney, 1995). Whereas shame is a universal emotional experience, there are individual differences in 
the strength and frequency that a person may experience the emotions (Tangney, 1995); this trait is called shame-proneness. The propensity for experiencing guilt is similarly referred to as guilt-proneness. This differentiation has important ramifications for measurement, as shame-proneness (a trait) will fluctuate between individuals, whereas the reported experience of shame (a state) fluctuates within individuals. The investigation of shame-proneness and the consequences thereof is important for understanding how this trait may impact individuals' attitudes and behavior. This is particularly important in light of ongoing research suggesting that shame-proneness can greatly impact work behaviors, and may be related to unethical decision making (Cohen \& Panter, 2015). Additionally, some research suggests that shame may be an opportunity for intervention to prevent immoral and unethical behavior in the future (as is the case with shame predicting criminal recitivism; Tangney, Stuewig, and Martinez, 2014).The present research sought to investigate shame-proneness specifically, due to it's potential impact in undermining work performance and health, and, as previous work suggests, significant practical applications.

The experience of shame has been the subject of much semantic nuance and debate (for a full review, see Tangney, 1996). Historically, there has been confusion as to whether guilt and shame are distinct emotions. In everyday terms, "shame" and "guilt" are used interchangeably. However, empirical evidence supports that the two are in fact very different. Both describe emotions that are considered detrimental, often characterized by dissatisfaction, anxiety, and regret. Occasionally these constructs are discussed for their potential positive impact, to be used and manipulated as tools of social 
regulation wherein an individual's behavior might be motivated by avoiding the experiences (e.g., historic public shaming, like medieval stocks, or the classic literary example of Nathaniel Hawthorne's The Scarlet Letter). However, to fully understand, one must appreciate the difference between guilt and shame as they are empirically supported by the work of Tangney (e.g., Tangney, 1994; Tangney, 1996; Tangney \& Dearing, 2003).

The experience of shame is demonstrated in feelings of exposure to an external or internal judgment, (Johnson, 2012) often described as an "observing other," "a sense of shrinking or of 'being small,' of sinking into the floor," a feeling that the situation in which one is embedded is completely out of control (Tangney, Miller, Flicker, Barlow, 1996, pp. 1256-1258). The experience of shame can be so painful for an individual that it is often described as "debilitating" because it affects one's core sense of self. Shame arises when an individual makes internal, stable or permanent, global attributions about the self. These attributions then lead to negative feelings about the global self (Tracy \& Robins, 2004). Conversely, guilt comes about when an individual makes internal, unstable or temporary, specific attributions about actions or behaviors. Guilt is a negative feeling about a specific event, rather than the self. These attributions may also lead to negative feelings, but they are specific to a behavior (Tracy \& Robins, 2004). Thus, shame and guilt can be conceptualized as opposites on a continuum where negative assessment of "behavior" versus "self" exist at either end. This can also be described as behavior focused ("I did a bad thing," guilt) as opposed self-focused ("I am a bad person," shame; Cohen et al., 2011). The most widely used measures of shame and guilt 
proneness (TOSCA-3; Tangney, Dearing, Wagner, \& Gramzow, 2000; GASP; Cohen, Wolf, Panter, \& Insko, 2011) rely on this self-behavior distinction.

Niedenthal and colleagues (1994) explore this self-behavior distinction in relation to "counterfactual thinking," wherein an individual inaccurately compares an event against reality; e.g., "I deserved it," and "It's all my fault" lines of thinking among victims of trauma are prototypical examples of shame-based, self-oriented counterfactual thinking. The authors reveal that shame-based thinking often results in the individual believing him or herself to blame for situations completely outside of his or her control, a phenomenon they describe as causal attribution and a "mental mutilation" (Niedenthal, Tangney, \& Gavanski, 1994, p. 585). One easily understood example is found in investigation of sexual trauma survivors (e.g., El Leithy, Brown, \& Robbins, 2006). In the authors' investigation of survivors of trauma, research revealed a preoccupation with alternative outcomes among these individuals. These counterfactual thoughts were categorized by "I" statements (e.g., "If only I had..."), illustrating the individuals taking on a burden of emotional responsibility for something one cannot control (in this case, the experience of assault). However, one compelling study found that individuals high in shame-proneness experienced much greater consequences following sexual trauma, than did those survivors who were lower in shame-proneness (Talbot, Talbot, \& Xin, 2004). This work suggests that, while certain experiences and situations may relate to an individual's feeling of shame, it is those individuals already more prone to experience shame (i.e., high in shame-proneness) who suffer the greater consequences. 
This self-behavior distinction is important not only for its impact on an individual's emotions, but also, and crucially for the present research, its impact on an individual's behavior. Extensive research supports that shame, characterized by 'I'm a terrible person" thoughts, is also characterized by withdrawal action tendencies (e.g., hiding). For example, Harris and Darby (2009) found that among patients who felt shamed by a doctor, over one-third did not return to that doctor. However, guilt, characterized by "I made a mistake" thoughts, is associated with reparative actions. Repair actions are behaviors which attempt to correct the mistake, including apologizing. Clearly, these differing behavior patterns result in respectively maladaptive and adaptive outcomes. Guilt has been empirically demonstrated to correlate with empathic behavior (Leith \& Baumeister, 1998) and constructive responses to anger (Tangney, Stuewig, \& Martinez, 2014). Guilt-prone individuals are more inclined to take responsibility for their actions, rather than to deflect blame onto others or onto elements of a given situation (Dearing, Stuewig, \& Tangney, 2005).

Shame, conversely, has been empirically linked to withdrawal behaviors (Cohen et al., 2011). Blatt and colleagues (1995) argue that this powerful and painful experience creates intense cognitive dissonance that may eventually alter the sense of self. Because shame includes a negative self-assessment, it is deeply tied to an individual's identity. This global assessment makes the problem fundamentally unsolvable, as there is no way for an individual to detach from the self. Shame then causes a cycle of anger and remorse toward the perceived defective self, creating more certainty in the reality of the perceived defect. Not surprisingly, this can create a vicious cycle where experiences of shame 
exacerbate shame-proneness. This sequence creates a "maladaptive perfectionism" (Blatt et al., 1995) characterized by an "all or nothing" approach to problem solving. This coping strategy has been demonstrated to lead to learned helplessness and severely decreased cognitive resources (Johnson, 2012). Some specific outcomes of this cycle include criminal recidivism (Tangney, Steuwig, \& Martinex, 2014), and addiction relapse among substance users, including recently sober alcoholics (Randles \& Tracy, 2013). Tangney and Dearing (2002) reported that high shame-proneness among fifth graders later predicted several problematic behaviors including risky driving, earlier initiation of drug and alcohol use, and lower likelihood of practicing safe sex upon becoming sexually active. Similarly, shame-proneness has been positively linked to substance use and abuse in adulthood (e.g., Dearing et al. 2005, Meehan et al. 1996, O'Connor et al. 1994).

Shame and Drinking

In discussing the apparent link between shame-proneness and alcohol problems, several theorists hypothesize that shame-prone individuals drink as a means of down regulating or coping with frequent and highly aversive experiences of shame and other negative emotions (e.g., Treeby \& Bruno, 2012), which is consistent with Hull's (1981) Self-Awareness Model of Alcohol Consumption. This has important consequences both for investigations of the state experience of shame, as well as for investigations of the trait of shame-proneness. Fossum and Mason proposed, "addiction and shame are inseparable" (1986). They contend that confronting shame and the notion of a "defective self" in the context of therapeutic environment is vital to the process of recovery, which 
has subsequently been empirically supported (e.g., Woien, et al., 2003). While their assertions provide an important starting point for the present research, it is important to note that the work of Fossom and Mason focuses primarily on addicted individuals, and fails to take into account how these emotional processes may relate to non-addicted use of substances. An additional shortcoming of this work is its presumed directionality, as the authors state that these experiences are part of the disease without exploring the possibility that it is a precursor.

Indeed, Tangney and Dearing (2002) argue specifically that individuals experiencing shame may drink as a means to numb the negative psychological experience, echoing the Self-Awareness Model (Hull, 1981). Further, after the awareness decreasing effects of the alcohol have abated, an individual may, in turn, feel more ashamed; thus, a negative cyclical pattern may emerge. These negative cycles are evident in several empirical works. For instance, Randles and Tracey (2013) found that among newly recovering alcoholics, shame correlated with relapse from sobriety. In their study individuals recruited through Alcoholics Anonymous who had been sober for less than 6 months were asked to "Describe the last time you drank and felt badly about it." Researchers found that those individuals who demonstrated nonverbal displays of shame while recounting the most recent negatively valenced drinking had significantly higher risk of relapse within 4 months.

Of greater interest to the present study, Dearing, Steuwig, and Tangney (2005) also investigated college students drinking behaviors in relation to shame-proneness. In two separate samples of students the authors found a significant positive correlation 
between alcohol use and shame-proneness. In regards to state shame, Mohr and colleagues (2010) demonstrated significant associations between discrete mood reports of shame (i.e., reporting felling "ashamed") and subsequent drinking using daily process data. These findings indicate a within-person relationship between shame and drinking. However, the current research plans to build on this work by relying on a multi-item, validated measure of shame-proneness for a between-person investigation of the relationship. Informed by this body of literature, the present research hypothesizes that shame-proneness will positively relate to increased alcohol consumption in part as a function of state shame. The relation between shame-proneness and reported state shame is under investigated, and this research contributes to the literature by proposing state shame as a mediating mechanism between shame-proneness and increased consumption.

While I predicted that people with higher levels of shame-proneness would consume more alcohol, certain situational contexts are be more likely to facilitate the expression of shame-proneness. Considering the negative-self-assessment nature of shame, I examined the role of a workplace construct that may elicit or exacerbate these feelings: role ambiguity. The current research proposed role ambiguity as a situational context that might amplify or increase the influence of shame-proneness on drinking. 


\section{Situational Context of Role Ambiguity}

In a seminal work by Snyder and Ickes (1985) the authors explore the concept of situational strength. Situational strength is describes as environmental cues that may alter behavior, despite the individual's personality. Specifically the authors purport that certain situations, which have high situational strength, may override personality. For example, extroversion or risk-taking behaviors may be reduced in particularly strong situations that dictate certain behavior. An example of a strong situation is a red traffic light, which dictates behavior clearly and precisely (i.e., to stop) no matter what. No matter how daring or cautious, almost all individuals stop at red lights. However, the opposite is true of weak situations, also referred to as ambiguous situations. Following the traffic analogy, an example of an ambiguous situation is a yellow light. State traffic laws differ on the meaning of a yellow light (stop or stop if able to safely), and cultural norms differ even further. These weak situations allow for greater expression of personality, where a persons daring or caution is more evident by their behavior.

Workplace role ambiguity may be exactly one of these weak situations as described by Snyder and Ickes (1985). In situations without clarity, norms are not well defined, and individuals' personality may be all the more evident and powerful in dictating behavior. The present research proposes that the presence of role ambiguity may allow for the strengthened expression of the trait of shame-proneness.

Many effects of prolonged role ambiguity are far-reaching and well documented. A seminal meta-analysis by Fisher and Gitelson (1983) clearly outlined problematic impacts of role ambiguity. The authors discuss role ambiguity's negative correlation with 
employee organizational commitment, job involvement, satisfaction with coworkers, satisfaction with promotions, and satisfaction with the work itself. An earlier work (Manning, Ismail, \& Sherwood, 1981) conducted within a laboratory demonstrated that role conflict actually caused dysfunctional affective, physiological, and behavioral outcomes.

Classical organization theory and role theory both address the concept of Role Ambiguity. According to classical organization theory, "every position in a formal organizational structure should have a specified set of tasks or position responsibilities" (Rizzo, House, \& Lirtzman, 1970, p. 151). The organizational structure outlined here greatly benefits organizations; it allows superiors to hold employees accountable for performance, which in turn improves organizational level performance, productivity, and profitability. However, this organizational structure also has tremendous benefit to the employee. When work expectations and performance standards are explicit, employees are empowered to make decisions within their scope, as well as improve performance by eliminating the need for a trial and error approach to meeting expectations (Rizzo, House, \& Lirtzman, 1970).

Role theory similarly explores themes of expectations. Kahn and colleagues (1964) discuss role ambiguity as a dearth of necessary information regarding an organizational position. Role ambiguity is considered a form of role conflict, wherein an employee is required to play two or more roles which conflict with each other (Van Sell, Brief \& Schuler, 1981). However, role ambiguity was not elaborately described in early literature (e.g., McGrath, 1976; Sarbin \& Allen, 1968). Kahn et al. (1964) most clearly 
define role ambiguity as the degree to which clear information is unavailable regarding (a) the expectations of the role, (b) the methods for best fulfilling known expectations, and/or (c) the consequences of failing to meet expectation (i.e., poor performance).

Ambiguous stressors are also empirically shown to be more likely to be appraised as stressful, relative to non-ambiguous stressors. Ambiguous stimuli do not prompt an individual to take action, because he or she must spend energy to trying to understand the stressor. This can be time consuming, and resource draining. The ability to take confrontative action is usually associated with less distress and better coping (Billings \& Moos, 1984).

Hallmarks of ambiguous work roles include a lack of clarity about expectations, behaviors, and consequences within a particular role (Rizzo, House, \& Lirtzman, 1970). One could reasonably expect this experience to create opportunities for uncertainty, insecurity, miscommunications and mistakes. Kahn and colleague's original work explicitly states that a common defense mechanism in response to experiences of role ambiguity is "the distortion of reality." The authors propose that when an individual does not know what is "right," he or she is always "wrong," no matter the outcome. That is, if positive feedback for good performance and correct outcomes are absent (as is the case with role ambiguity), an employee will consider all actions equally, and is unable to determine what is most effectively contributing to positive outcomes. As a result, role ambiguity is a self-compounding issue.

Considerable literature thereafter also supports the complex ways in which role ambiguity decreases job performance, task performance, and creates opportunities for 
mistakes. It is for this reason in particular that role ambiguity in the workplace lends itself for consideration as a moderator of shame-proneness. The context of role ambiguity is potentially rife with opportunities to discern guilt (negative behavior evaluations and repair actions) from shame (negative self-evaluations and withdrawal behaviors) proneness, and to see particularly powerful impacts of shame. Theory suggests that shame-prone individuals, following negative outcomes, are more likely to make negative assessments of the self, rather than of the behavior or situation, thus experiencing greater shame in response to negative outcomes.

However, the most salient point from this culmination of research is the understanding of role ambiguity as a cause of stress or tension. For example, C.L. Cooper, Mallinger, and Kahn (1978) found among a population of dentists that a high level of conflict originating from the dentist's idealized goals (around caring for and healing patients) and the actuality of their infliction of pain during dental procedures was a major predictor of abnormally high blood pressure. This conflict of goals and feedback provides a poignant example of role ambiguity. This unpleasant experience results, Kahn et al. (1964) stipulate, in behavioral adaptation, which will lead to increased stress or tension. According to role theory, role ambiguity increases employee dissatisfaction with his or her role, as well as increases anxiety and subsequently decreases performance. Specifically, employees may attempt to solve problems outside the assigned scope of work in order to avoid the source of stress, anxiety, and uncertainty.

A crucial point for the present proposal is that the stress, anxiety, and uncertainty that is present under conditions of workplace role ambiguity, will likely affect shame- 
prone individuals differently than individuals who are not shame-prone. Social cognition literature demonstrates that certain contexts make different affective experiences more salient (e.g., Turner, Oakes, Haslam, \& McGarty, 1994). Relying on the theoretical framework provided by Snyder and Ickes (1985) of situational strength, it seems likely that the situation of role ambiguity will serve as an amplifier of the predicted outcomes of the personality trait of shame-proneness.

\section{The Present Research}

The present research sought to examine the direct relationship between shameproneness and drinking behaviors. In line with previous research, which supports the notion that experiences of shame predict increased alcohol consumption (e.g., Dearing et al., 2005; Randles \& Tracy 2013), this study investigated the more stable trait of shameproneness and alcohol involvement. Additionally, in light of the opportunities for misdeeds and transgression in the presence of recent workplace role ambiguity, I proposed that shame-prone individuals (through the tension reduction hypothesis) would be more affected by the presence of role ambiguity, and thus experience greater alcohol involvement. 


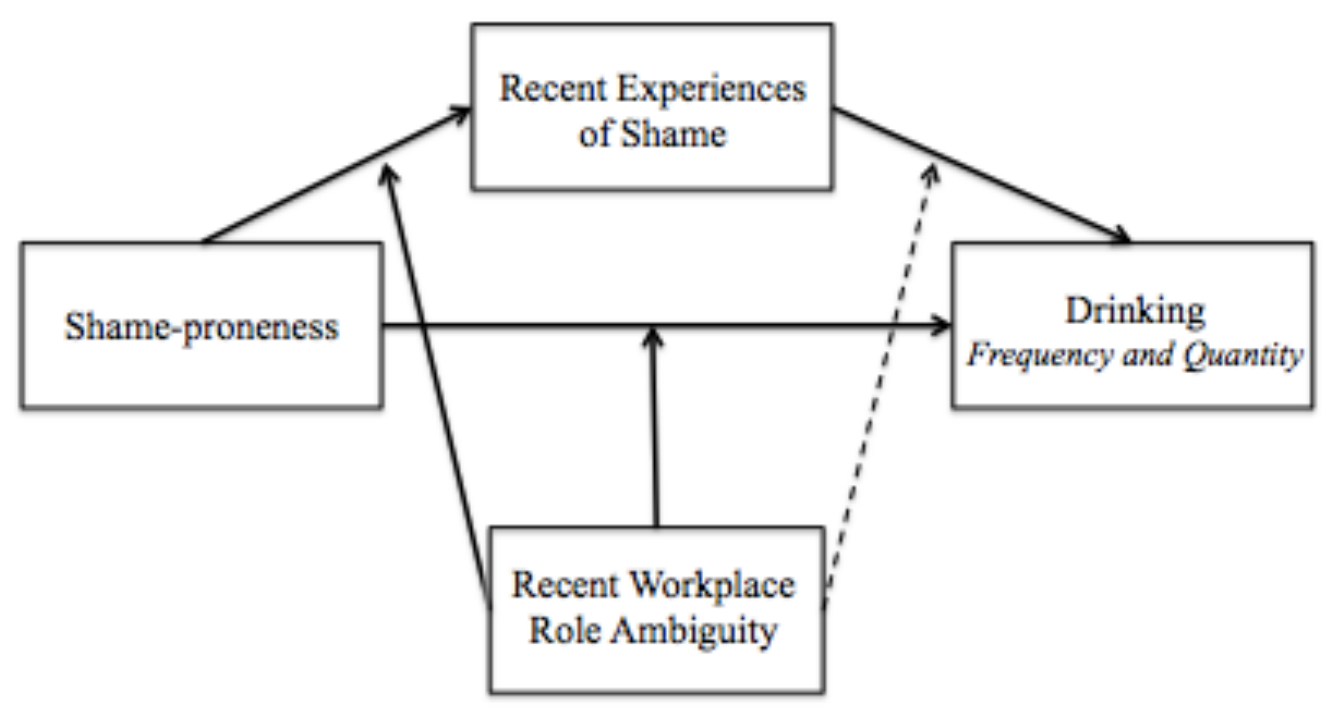

Figure 1: Conceptual Model

Specifically, I was interested in the following research questions: How does shameproneness relate to drinking behaviors? Do shame-prone individuals, in the presence of workplace role ambiguity, have greater alcohol involvement relative to those individuals not experiencing role ambiguity?

\section{Hypotheses}

Hypothesis 1a-b: Consistent with the tension-reduction hypothesis, I hypothesized a significant positive direct effect of shame-proneness on alcohol consumption (a) frequency and (b) quantity, such that higher levels of shame-proneness would associate positively with higher levels of alcohol consumption.

Research and theory support the link between shame experiences and drinking behaviors (e.g., Treebly \& Bruno, 2012). Work by Tangney and Dearing (2002) elucidate the process by which individuals experiencing shame may drink as a method of numbing 
the negative feelings associated with this negative psychological experience. Dearing and colleagues (2005) support theory that shame-prone individuals are vulnerable to a variety of problems associated with maladaptive coping, specifically demonstrating increased alcohol consumption and substance use (as opposed to their guilt prone counterparts). The present research sought to investigate the relationship between the trait of shameproneness and frequency and quantity of alcohol consumption. It was anticipated that shame-prone individuals would report greater alcohol consumption.

Hypothesis 2: I predicted a significant positive effect of the trait of shame-proneness on reported experiences of state shame.

Hypothesis 3a-b: I predicted a significant positive effect of the state emotional experience of shame on alcohol consumption (a) frequency and (b) quantity.

Hypothesis 4a-b: I predicted a significant indirect effect of shame-proneness on alcohol consumption (a) frequency and (b) quantity through state experiences of shame, such that higher shame-proneness had a conditional indirect effect on alcohol consumption. Hypothesis 5a-b: I predicted a significant moderated mediation of the indirect effect model enumerated in hypothesis 4, such that the relationships in hypotheses 1 and 2 depended on levels of workplace role ambiguity.

a) I predicted a significant moderation effect of role ambiguity on the direct effect of shame-proneness on alcohol consumption, such that higher rates of role ambiguity would promote high levels of drinking frequency (a1) and quantity (a2) 
SHAME-PRONENESS, DRINKING BEHAVIORS, AND ROLE AMBIGUITY

b) I predicted a moderation effect of role ambiguity on the relationship between shame-proneness and experiences of shame, such that greater role ambiguity would positively relate to experiences of state shame.

Social cognition literature demonstrates that certain contexts make different affective experiences more salient (e.g., Turner, Oakes, Haslam, \& McGarty, 1994). I hypothesized that role ambiguity is one of those contexts, and that role ambiguity would moderate the relationship between shame-proneness (trait) and shame (state). Specifically, individuals experiencing workplace role ambiguity would demonstrate a stronger connection between shame-proneness and experiences of shame, relative to those individuals experiencing lower levels of role ambiguity. Said another way, the context of workplace role ambiguity would strengthen the salience of self-assessment for shame-prone individuals, thereby increasing the experience of state shame.

The experience of workplace role ambiguity offers an opportunity to study how shame-prone individuals may be uniquely impacted by this negative experience. Role ambiguity has been empirically linked to decreased task and job performance (e.g., Yun, Tacheuchi, \& Lui, 2007), indicating that mistakes and misdeeds are indeed occurring. Extensive literature on shame-prone individuals support that those persons are more likely to make a highly painful negative self-evaluation following misdeeds or transgressions, rather than a less painful negative behavior evaluation. Perhaps more important for the present research, however, is the theoretical lens proposed by Kahn et al. (1964) which suggests the presence of role ambiguity creates a "distorted reality." In the absence of clear expectations, guidance, and feedback that would allow an employee 
to properly accomplish his or her job, even when an employee does something correctly he or she does not know it. The presence of role ambiguity means that even if no misdeeds or transgressions are present, the employee may believe that they are in the absence of feedback to the contrary.

Research Question 1: In addition to the above hypotheses, I proposed to investigate the following research question: Does workplace role ambiguity impact the relationship between experiences of state shame and alcohol involvement? Although there is insufficient evidence to propose a directional hypothesis, there is reasonable support for the potential for a relationship. Thus, I proposed this moderated relationship. 


\section{Methods}

Overview

To investigate these hypotheses, I conducted a secondary analysis of data collected through a larger study examining student interpersonal relationships, stress, emotional experiences, and health behaviors, directed by Cynthia Mohr, Ph.D. This survey took students approximately 45 minutes to complete. Students were recruited through the psychology department, and received extra-credit for participating. The survey was designed and implemented online using Qualtrics survey software.

\section{Participants}

Participants were undergraduate students at a large university in the Pacific Northwest participating in the larger survey project. The current research relied on a subsample that includes only those students who are employed for pay in addition to their role as students. The project surveyed 395 students, $60.0 \%$ of whom were employed $(n=$ 237). Sixty five percent of employed students reported consuming alcohol within the last 30 days, thereby creating a sample size for the current study of 155 student workers who reported consuming alcohol. Among these workers mean hours worked are $23.4(S D=$ $10.0)$ with an average time at primary job of 1.7 years $(S D=3.0)$. See Table 1 for more additional employment details. A strength of this sample is that it represents a larger diversity of age than is typical of college student sample $(M=26.4, S D=7.6)$. Reflective of the larger university population, participants were mostly female and while $(79.4 \%$ female, $70.3 \%$ non-Hispanic White). While a majority of participants (78.8\%) report 
attending the university for fewer than two years, most of them reported Junior or Senior standing (78.8\%). See Table 1 for more complete participant descriptive information.

Participants also reported the average number of hours worked per week, the length of time at current place of employment, and how many employees the participant supervised (See table 1). A majority of these workers self-identified as Managers (25.8\%), Service workers (22.6\%), Professional (including licensed and office/clerical; $16.1 \%)$ and Sales (12.3\%).

\section{Measures}

\section{Employment Information}

In addition to demographic information, a series of employment questions were asked to determine the subsample, as these analyses were limited to only those participants who also hold employment outside of student status. Questions, which specified the participants' primary job (note that $22.4 \%$ reported working more than one job), included the open ended "What is your job title?" and the categorical "What is your job type?"

\section{Drinking Behaviors}

Alcohol use was assessed using items to capture quantity and frequency during the past 30 days. Initially participants were asked "Have you consumed any alcohol in your lifetime?" and "Have you consumed any alcohol within the past 30 days?"

Participants who answered positively to both of those questions were also asked to answer more detailed questions about their drinking habits. Participants were instructed as to the size of a standard drink (One drink - $12 \mathrm{oz}$. beer, or $5 \mathrm{oz}$. wine, or $1.5 \mathrm{oz}$. 
liquor/mixed drink; NIAAA, 2004), and subsequently asked "How many days in the past 30 did you consume any alcohol?" (referred to as "Frequency") and "On days where you did drink in the past 30 days, how many drinks did you have on average?" (referred to a "Quantity"). Response options for frequency are continuous from 0-30 (i.e., days in a month), and for quantity are whole numbers from $0-7$, and " 8 or more" (i.e., drinks consumed). The present research relied on Alcohol Frequency and Alcohol Quantity as the primary outcomes.

\section{Shame and Shame-proneness}

Shame-proneness was measured with the Guilt and Shame-proneness Scale (GASP; Cohen, Wolf, Panter, \& Insko, 2011). This sixteen-item scale presents short scenarios to participants, and asks participants to rank the likelihood on a 1 (very unlikely) to 7 (very likely) scale. These scenarios explore shame and guilt differently; examples are "While discussing a heated subject with friends, you suddenly realize you are shouting though nobody seems to notice. What is the likelihood that you would try to act more considerately toward your friends?" and "You successfully exaggerate your damages in a lawsuit. Months later, your lies are discovered and you are charged with perjury. What is the likelihood that you would think you are a despicable human being?" The sixteen scenarios create 4 subscales (scored by averaging the four items in each sub scale, and discussed further in the analysis plan section below). The subscales are Guilt: Negative Behavior Evaluation (NBE), Guilt: Repair (first example above), Shame: Negative Self-Evaluation (NSE, second example above), and Shame: Withdraw. One subscale, shame: negative self-evaluation, fits more conceptually clearly with these 
theoretical arguments. For the present research I operationalized shame-proneness through the shame: negative self-evaluation subscale (appendix A), and relied on the mean scores of that subscale to identify the shame-proneness of participants.

Shame was measured using the Positive and Negative Affective Scale (PANAS; PANAS; Watson et al., 1988). "Ashamed" was included as one of the negative affect items, where participants responded to "In the past 7 days, how much were..." with a five-point Likert scale $(1=$ Not at all to $5=$ Extremely $)$ response option. Previous literature has also relied on this single item measure (e.g., Mohr et al., 2008; Mohr et al., 2010).

Role Ambiguity

Role ambiguity was measured by the validated subscale of the Role Conflict Scale (Rizzo, House, \& Lirtzman, 1970). This six-question scale utilizes a five-point likert-type response $(1=$ Strongly disagree through $5=$ Strongly agree $)$ to respond to statements regarding the clarity of work and expectations in the work role (e.g., "I know what my responsibilities are" and "I know exactly what is expected of me;" Carlson, Kacmar, \& Williams, 2000; appendix B). This measure was reverse scored, so that higher scores reflect higher ambiguity.

Analysis Plan

To examine my hypotheses I utilized the PROCESS Macro for SPSS (Hayes, 2013; Model 59, see Figure 2), which included conducting four separate regression analyses for each outcome variables. Unlike previous methods of examining moderated mediation (e.g., Baron \& Kenny, 1986) the PROCESS method does not require step by 
step analyses, and examines all pathways concurrently. Due to the inclusion of tests of moderation, all variables were centered around their respective means (as recommended by Tabachnick \& Fidell, 2007), as centering reduces concerns of multicollinearity. In order to calculate and establish confidence intervals for the significance of conditional indirect effects, the PROCESS macro conducted bias-corrected bootstrapping. This accounted for potential non-normality in estimates (Hayes, 2013; Preacher et al., 2007). My hypothesis would be affirmed if the confidence intervals excluded zero.

The PROCESS macro for SPSS handles missing data in such a way that listwise deletion is not necessary, and therefore we were able to proceed with analyses in the case of missing data. In this case, however, there were no missing data among study variables. Prior to conducting analyses to investigate my hypotheses, the first step was to examine internal consistency of the measures (alphas). Alpha coefficients tend to show lower reliability in scenario-based measures because each individual item contains variance for the scenario, as well as for the construct being measured by the response (Tangner, 1996; Tangney \& Dearing, 2002). The GASP negative self-evaluation scale measuring shame-proneness had relatively low internal consistency $(\alpha=0.67)$, although it is comparable to previous work with the measure (e.g., $\alpha=0.69$ and $\alpha=0.71$ of Study 1 and Study 2 of Cohen et al., 2011). The reverse coded Role Clarity Scale (Rizzo et al., 1970), measuring role ambiguity revealed itself to be internally consistent $(\alpha=0.90$, compared to $\alpha=0.78$ and $\alpha=0.81$ in the original validation sample; Rizzo et al., 1970). 


\section{Results}

\section{Preliminary analyses}

I examined the distributions of variables by reviewing frequencies histograms and descriptive statistics of all variables of interest (Mertler \& Vanatta, 2005; Howell, 2013). I found that both state shame and role ambiguity had less variability than observed in other samples. One reason for this is that there seems to be higher reports of of participants who do not endorse state shame or role ambiguity (i.e., with $51.6 \%$ of respondents did not report experiencing state shame, and $46.5 \%$ reported no role ambiguity). Furthermore, several of the cariables deviated from normality. State shame had a skewness of $1.4(S E=0.20)$ and kurtosis of $1.19(S E=0.39)$, while role ambiguity had a skewness of $0.99(S E=0.20)$ and kurtosis of $1.06(S E=0.39)$. The GASP measure of shame-proneness revealed this sample to be high in shame-proneness, and thus the distribution is negatively skewed, $-1.07(S E=0.20)$ and kurtosis of $1.16(S E=0.39)$. This skewness suggests a higher median than mean.

Mean alcohol consumption must be interpreted carefully as it is common to have outliers (e.g., individuals who consume with both high quantity and frequency). Mean number of days participants consumed alcohol in the last 30 was $8.52(S D=7.53)$, and mean number of drinks on average was $2.73(S D=1.71)$. These means differ from previous samples (e.g., Mohr et al, 2005). These students appear to drink more frequently, but less in quantity (compared to 3.85 days out of 21, and 5.91 drinks per day as reported by Mohr and colleagues). These data were examined carefully for outliers. Visual inspection of the frequencies histogram revealed both variables non-normally 
distributed, as was to be expected. In addition to visual inspection of the data, I looked for outliers that were three standard deviations above the mean. No such outliers existed for frequency outcomes. Eight data points occurred more than three standard deviations above the mean for quantity, and examination of a box and whisker plot revealed the same eight data points as outliers. Outliers were retained to maintain sample size. Posthoc analyses excluding outliers did not yield different results.

Prior to hypothesis testing, I explored the correclations among the study variables. ( Correlations matrix presented in Table 2). Shame-proneness, as measured by the GASP, did not correlate with any of the other variables in the model, most notably state shame. As aforementioned, there is significant zero inflation of reported state shame, which may account for this result. Role ambiguity appears not to correlate significantly with any key variables, which is contrary to expectation. As expected, drinking frequency and drinking quantity were modestly correlated. However, correlations of this magnitude may indicate that participants are engaging in binge drinking (i.e., high quantity at low frequency).

\section{Hypothesis Testing}

To test my hypotheses I relied on the PROCESS macro for SPSS. Additionally, previous work indicates that alcohol consumption is impacted by both age and gender (through the stressor vulnerability model; e.g., Cooper et al., 1992a; Armeli et al., 2000), and thus these analyses controlled for both. Note that the PROCESS method also controls for all variables in the model (see figure 2 for example). Results of the test are as follows, and are represented in Table 3 and 4. 
Drinking Frequency The results of the model predicting drinking frequency as the distal outcome are presented in table 3. Contrary to hypothesis 1a, no significant effect of trait shame on drinking frequency was observed controlling for the other predictors and evaluated at the grand mean of role ambiguity $(B=-1.82,95 \%$ BC CI $[-4.13 ; 0.49])$. Contrary to hypothesis 2 , no significant effect of trait shame on state shame was observed when controlling for the other predictors and evaluated at the grand mean of role ambiguity $(B=-0.10,95 \%$ BC CI $[-0.45 ; 0.26])$. Contrary to hypothesis 3 a, there was a significant effect of state shame on drinking frequency observed when controlling for the other predictors and evaluated at the grand mean of role ambiguity, but in the opposite direction hypothesized $(B=-3.56,95 \%$ BC CI $[-6.19 ;-0.94])$. Finally, in contrast with hypothesis $4 \mathrm{a}$, the indirect effect of trait shame on drinking frequency through state shame was not statistically significant when controlling for the other predictors and evaluated at the grand mean of role ambiguity $\left(B_{\text {indirect }}=-0.008,95 \%\right.$ BC CI $[-0.18$; 0.10]. Thus hypotheses 1a, 2, 3a, and 4a were not supported.

In contrast with hypothesis 5a1, role ambiguity did not significantly moderate the effect of trait shame on the outcome of drinking frequency when controlling for the other variables in the model $(B=.42,95 \%$ BC CI $[-0.70 ; 1.55])$. In contrast with hypothesis $5 b$, role ambiguity did not significantly moderate the effect of trait shame on state shame when controlling for other variables in the model $(B=.06,95 \% \mathrm{BC}$ CI $[-0.11 ; 0.23])$. Thus hypotheses $5 \mathrm{a} 1$ and $5 \mathrm{~b}$ were not supported. Addressing research question 1a, role ambiguity significantly moderated the effect of state shame on drinking frequency when controlling for the other predictors in the model $(B=1.56,95 \%$ BC CI $[0.45 ; 2.67])$. See 
figure 3 for a graphical depiction of the interactive effect. The relationship between state shame and drinking frequency is more strongly negative for those with more role ambiguity. For example, for those individuals with lower ambiguity (those one standard deviation below the mean), higher levels of state shame were related to lower drinking frequency $(b=-4.84, p<.01)$.

\section{Drinking Quantity}

The results of the model predicting drinking quantity as the distal outcome are presented in table 4. Contrary to hypothesis $1 \mathrm{~b}$, no significant effect of trait shame on drinking quanity was observed controlling for the other predictors and evaluated the grand mean of role ambiguity $(B=-0.09,95 \% \mathrm{BC}$ CI $[-0.65 ; 0.46])$. As presented above, contrary to hypothesis 2 , no significant effect of trait shame on state shame was observed when controlling for the other predictors and evaluated at the grand mean of role ambiguity $(B=-0.10,95 \%$ BC CI $[-0.45 ; 0.26])$. Contrary to hypothesis $3 \mathrm{~b}$, there was a significant effect of state shame on drinking quantity observed when controlling for the other predictors and evaluated at the grand mean of role ambiguity, but in the opposite direction hypothesized $(B=-0.64,95 \%$ BC CI $[-1.27 ;-0.001])$. Finally, in contrast with hypothesis $4 \mathrm{~b}$, the indirect effect of trait shame on drinking quantity through state shame was not statistically significant when controlling for the other predictors and evaluated at the grand mean of role ambiguity $\left(B_{\text {indirect }}=-0.001,95 \%\right.$ BC CI $[-0.04 ; 0.02]$. Thus hypotheses $1 \mathrm{~b}, 2,3 \mathrm{~b}$, and $4 \mathrm{~b}$ were not supported.

In contrast with hypothesis 5a2, role ambiguity did not significantly moderate the effect of trait shame on the outcome of drinking quantity when controlling for the other 
variables in the model $(B=-0.004,95 \%$ BC CI $[-0.28 ; 0.27])$. As reported above, in contrast with hypothesis $5 \mathrm{~b}$, role ambiguity did not significantly moderate the effect of trait shame on state shame when controlling for other variables in the model $(B=.06$, 95\% BC CI $[-0.11 ; 0.23])$. Thus hypotheses $5 \mathrm{a} 2$ and $5 \mathrm{~b}$ were not supported. Addressing research question $1 b$, role ambiguity significantly moderated the effect of state shame on drinking quantity when controlling for the other predictors in the model $(B=0.28,95 \%$ BC CI $[0.01 ; 0.55])$. See figure 4 for a graphical depiction of the interactive effect. The relationship between state shame and drinking quantity is more strongly negative for those with more role ambiguity. At one standard deviation below the mean of role ambiguity there is a significant negative association between state shame and drinking quantity $(b=-.87, p<.05)$.

The test of the model predicting drinking frequency was significant $\left(R^{2}=.17, p<.001\right)$, but the model predicting state shame was not significant $\left(R^{2}=.04, p=.30\right)$. However, the model predicting drinking quantity was not significant $\left(R^{2}=.05, p=.30\right)$. I hypothesized that shame-proneness (i.e., trait shame) would predict drinking frequency (hypothesis 1a, see Table 3) and drinking quantity (hypothesis 1b, see Table 4). However, results indicated that the direct effect was not significant (Frequency: Quantity:.

I also hypothesized a significant positive direct effect of trait shame-proneness on reported experiences of state shame (hypothesis 2; see Table 3), however results indicated that there was no direct effect Thus it appears that shame-proneness does not predict state shame as measured. 
Similarly, I predicted a positive effect of state shame on drinking frequency (hypothesis 3a; see table 3) and quantity (hypothesis $3 b$; see table 4). These analyses revealed both pathways significant Quantity:). However, these results must be interpreted carefully. The PROCESS model controls for all other variables in the model, meaning that these results suggest state shame controlling for shame-proneness predict drinking. Noting that the zero order correlations between state shame and drinking outcomes was also non-significant, these results do not support the hypothesis.

It was also hypothesized that there would be a significant indirect effect of shameproneness on alcohol consumption frequency (hypothesis $4 a$ ) and drinking quantity (hypothesis $4 \mathrm{~b}$ ) through state experience of shame. To test this hypothesis I relied on PROCESS Model 4, which is a simple mediation model (no moderators, which in this instance means these analyses did not control for role ambiguity). Results revealed there to be no significant indirect effect of shame-proneness, through state shame, on either drinking frequency $(B=-0.001,95 \% \mathrm{BC} C \mathrm{CI}[-0.14 ; 0.09])$, nor on drinking quantity $(B=$ $-0.001,95 \%$ BC CI [-0.03; 0.01]).

Lastly, I predicted a significant moderated mediation of the indirect effect model outlined above. Specifically, I hypothesized that workplace role ambiguity would moderate the direct effect of shame-proneness on alcohol consumption frequency (hypothesis 5a1) and quantity (hypothesis 5a2). The test revealed a significant moderation effect of mean levels of role ambiguity on the direct effect of shameproneness on drinking frequency $(\mathrm{p}<.05,95 \% \mathrm{CI}[-1.99 ;-0.02])$. For individuals experiencing mean and low levels of role ambiguity, lower levels of state shame were 
inversely related to drinking frequency $(b=-1.34, p<.04)$. The test for quantity was nonsignificant $(p>.05,95 \% \mathrm{CI}[-0.04 ; 0.02])$. I also predicted that role ambiguity would moderate the relationship between shame-proneness and state shame (hypothesis $5 \mathrm{~b}$; see table 3), however, results did not reveal a significant interaction

One research question was posed, with no hypothesis of directionality of the effect. I tested whether workplace role ambiguity had any impact on the relationship between state shame and drinking frequency (Research Question 1a; see table 3) and quantity (Research Question 1b; see table 4). The test revealed that there is a significant interaction between state shame and role ambiguity predicting drinking frequency For those individuals with lower ambiguity (those one standard deviation below the mean), higher levels of state shame were related to lower drinking frequency $(b=-4.84, p<.01)$. Similarly, for individuals with high role ambiguity higher levels of state shame were also negatively related to drinking frequency $(b=-2.29, p<.05$; see figure 3$)$. A similar interaction was detected between state shame and role ambiguity predicting drinking quantity (However, the interaction is not significant for those individuals with higher role ambiguity $(b=-.41, p=.07)$.

The nature of the PROCESS analytic strategy is that all variables in the model are controlled for simultaneously (see figure 2). In the case of the present research, this means that the above interactions (between role ambiguity and state shame relating to drinking) were controlling for shame-proneness. As shame-proneness and state shame are theoretically closely related to one another, post-hoc analyses were employed to test the 
interactions individually, without controlling for shame-proneness. These analyses, however, did not yield different results. 


\section{Discussion}

I expected there to be a relationship between shame-proneness, through state shame, and alcohol consumption. I also anticipated that relationship would be moderated by experiences of workplace role ambiguity. The results of these analyses revealed, however, that should that relationship exist, it is not captured by these methods. Unfortunately these results did not support the hypotheses as anticipated. Additionally, the research question posed was supported in the opposite direction that theory and previous work would suggest. There may be several reasons that this is the case, and in the spirit of informing future research, are enumerated below.

Extensive research supports the experience of workplace role ambiguity as stressful, and as an opportunity for self-reflection and evaluation. However, as the current research does not explicitly measure self-evaluation, its mediating effect on the potential relationship between shame-proneness and role ambiguity is merely theoretical. Additionally, there may be more meaningful differences in how individuals experience workplace role ambiguity, or how those juggling multiple roles experience it. A few notable works suggest that for some individuals' role ambiguity may be positive, particularly for those with highly creative jobs that require greater autonomy. Shenkar and Zeira (1992) demonstrated that among a sample of CEOs, ambiguity around their work roles increased feelings of autonomy, decision-making, and motivation, leading to overall increases in creativity and productivity. While it was not anticipated that this would be the experience of student workers, in light of the present results more investigation is warranted. It may be tempting to believe that role ambiguity may not be 
as painful or stressful in low-level jobs (i.e., that some employees "don't care"), or for employees without tenure in their jobs. However, both theory and previous work refute this notion (e.g., Rizzo et al., 1970). While we cannot assume that role ambiguity among this sample may not be problematic, it is possible that another factor is contributing to the low variance in role ambiguity. Perhaps there is something about the jobs held by these individuals that may not be conducive to experiences of role ambiguity (i.e., low ambiguity positions). Future investigations may also benefit from a different measure of types of employment, or a focus on specifically ambiguous work. The present research utilized Department of Labor categorization of types of employment, and a college students sample may benefit from a more limited range where options contain more nuance.

Another possible reason for unfavorable findings could be related to power and precision. This sample is an admittedly small one for relying on a complex psychometric measure like the GASP, and low power could be partly to blame. However, with this sample size it is not possible to run a confirmatory factor analysis to confirm the factor validity of the measure. Additionally related to sample size, this sample demonstrates likely patterns of binge drinking, reporting mean frequency at only 8.71 days per month (which is comparable to other student samples, e.g., Wechsler \& Nelson, 2001). Binge drinking incidents usually suggest that a larger sample is necessary to observe the effects of predictors on less frequent drinking.

Relating to precision, alcohol researchers have found that drinking context may make a difference in individuals' drinking experience. Drinking at home alone (i.e., 
solitary drinking) is an empirically different experience than going out for drinks with friends (i.e., away from home and in social context). The present research did not account for drinking context, and future research may benefit from doing so. There is some evidence that indicates that shame may, in fact, be related only to solitary drinking (Mohr et al., 2008). Therefore, it is possible that shame is positively related only to solitary consumption, and negatively related to social consumption, which could account for nonsignificant findings when not accounting for context. It may also be possible that drinking phenomena are different for underage drinkers, although post-hoc analyses reveal that excluding underage drinkers did not improve trends toward statistical significance. Similarly, the mean age of this sample may suggest that this group of students may not represent a "typical" college student experience, as we may see among a younger or more traditionally aged group. The significant interactions here ran in a direction contrary to what theory would suggest. In fact, as shown in figure 3 , it appears that higher role ambiguity may promote an adaptive response: in individuals where role ambiguity is higher, drinking is lower, which is precisely what an individual should be doing when cognitively taxed at work. However, as the results do run contrary to previous findings, they must be interpreted with caution. It is possible that there may be an issue of a missing third variable, in this case, drinking context. Research suggests (e.g., Mohr et al., 2001) that mechanisms surrounding solitary drinking (as opposed to drinking with others) may be unique, and particularly influences by social emotions. Therefore, future research would do well to consider context more heavily when examining social emotions (like shame) in relation to drinking behaviors. 
While the developers of the GASP make a compelling case for the measure, the reliability of the scale is low, and the distribution negatively skewed. Oddly, post-hoc analyses revealed that the reliability of all 8 shame-proneness items (negative self assessment and withdrawal subscales) increase reliability $(\alpha=0.77)$, and inclusion of all 16 measures (both the shame-proneness and guilt-proneness subscales) increases reliability still further. Future research, with a larger sample size, would be well advised to conduct a confirmatory factor analysis to ensure the validity of these subscales. Future research may also be able to more clearly articulate these relationships through more multifaceted measures.

Of particular surprise to the author, was the lack of relationship between shameproneness and state shame as measured here. However, there is a body of literature indicating that states and traits may not correlate as closely as one might anticipate, and perhaps that is the case here in the lack of significant correlation between shameproneness and state shame. Within-person measurements of mood reveal greater variance in mood experience than do single time point measures inviting participants to recall their mood over a period of time (as was utilized in this study; Cranford, Shrout, Iida, Rafaeli, Yip, \& Bolger, 2006). While this cross sectional investigation revealed a low reports of state shame, within-person investigations reveal greater variance and higher reports of the experience. It is possible that this sample did in fact experience state shame, but that these cross sectional methods were inadequate for capturing it.

Another possible explanation is that the existence of shame could impact the selfreport of individuals. There is evidence to suggest that high instances of shame may 
report in less truth telling, which in this case could be reports of consumed alcohol. White the interactions revealed by the present research suggest that higher shame and higher role ambiguity may be related to lower consumed alcohol, it is important to consider that they are in fact only related to lower reported alcohol consumption. Some literature suggests that higher rates of shame and shame proneness are related to higher instances of amoral behavior, like truth telling.

Finally, there is the likely issue of measurement. Using a single item measure for state shame (the mood measurement, PANAS), may be limiting. While it is common practice in mood literature to do so, shame is a multifaceted emotion that is arguably more complex than other moods (e.g., sad, angry, etc). Additionally, shame is a semantically complex concept, and the word "ashamed" may not mean the same thing to all individuals, and may not map onto the latent construct as defined by empirical research. This possibility is supported by significant zero-inflation of reported state shame. While research and theory alike suggest that shame is a universal emotion, $51.6 \%$ of participants reported experiencing no shame in the past 7 days.

Another possibility, however, it is that positive mood buffered against the negative mood of shame. Previous literature (e.g., Mohr, et al., 2008) also tells us that positive moods may buffer against negatively valenced moods. It is possible that positive mood experiences are washing out the reported experiences of shame, particularly since the mood measurement is limited to between-person. It is also noteworthy that there may be a link between guilt and drinking, however, Mohr and colleagues (2008) found that when controlling for shame, guilt no longer predicted drinking outcomes. Those findings 
suggest that it is the possible shared valence between the two that may predict negative affective drinking. Future investigations may consider possibilities for better capturing that shared valence.

Another factor that may obfuscate these results, and is cause for concern, are posthoc results revealing that there are no significant gender difference in drinking outcomes. An independent samples $t$ test revealed no significant gender difference in mean number of drinks per day (2.82 for men versus 2.70 for women), $t(149)=.35, p>.05$, nor the mean number of days drinking per month $(8.71$ for men versus 8.40 for women $), t(149)=$ $.20, p>.05$. Significant literature indicates that men and women process alcohol differently (e.g., Cooper et al., 1992a), and should therefore consume alcohol at difference levels (e.g., Wilsnack, Wilsnack, Kristjanson, Vogeltanz-Holm, and Gmel, 2009). The CDC recommends maximum daily consumption for men of two standardized drinks per day, while for women the recommendation is one drink per day. (U.S. Department of Health and Human Services, 2015). There is growing evidence that college women are consuming more and more, to match the consumption of their male peers, which is cause for great concern. While this sample is predominantly female (79.3\%), an indent t-test of means of alcohol consumption between men and women revealed no significant differences in their drinking frequency or quantity.

While this investigation did not reveal the hypothesized relationships, the findings seen here demonstrate that there is merit to the questions, and that further investigation is needed to more clearly demonstrate what these relationships might be. 


\section{Limitations}

Cross sectional research certainly has its limitations, and this may be a prime example thereof. Simply put, between-person investigations may be insufficient for measuring state shame. Prior studies that investigate within-person differences have made compelling cases for the shame-drinking connection on the daily level (e.g., Mohr et al., 2008). For future investigations daily data collection would likely reveal a more nuanced story.

Similarly, larger sample size may be important for future research, to ensure that complex and nuanced phenomena may be captured and confirmed statistically. This research may also have limited generalizability, as this sample is older than traditionally aged college student samples.

\section{Implications}

As noted above, the demonstration of the impact of role ambiguity on the relationship between shame-proneness, shame, and drinking behaviors has the potential for meaningful application in workplaces to improve total worker health. While this investigation did not support the hypotheses posed, strong theoretical connection between the constructs, and some counter-theoretical findings here offer support for future research. Previous research supports the notion that state shame may be malleable through shame-proneness interventions, which could improve the negative outcomes empirically associated with shame. Similarly, a successful investigation into these constructs could provide rich information for universities to apply to support their working students. While there is no demonstrated relationship as measured in this 
investigation, a demonstrated relationship in the future between shame-proneness and drinking behaviors would offer insight into the long-studied, complex mechanisms that predict drinking behaviors. This investigation steers future research to carefully consider within person experiences of shame and drinking, as well as how drinking context may play a role in the shame-drinking connection. Additionally, the incorporation of work role ambiguity and its potential influence on drinking behaviors would be a tremendous impact the field of Occupational Health Psychology.

Regardless of the causal direction, a demonstrated relationship between shameproneness and alcohol use in the context of a working population has important ramifications for potential workplace based interventions. Even though this research does not illuminate whether shame and shame-proneness are related to drinking behaviors, future research, specifically that focusing on within-person variance of these constructs may have more success.

The investigation of the relationship between shame-proneness and drinking behaviors, considering the context of the workplace, is overdue. This study was among the first to investigate the association specifically between shame-proneness and drinking behaviors among a working sample. Additionally, this study was the first known to this author to investigate how a workplace construct may interact with shame-proneness. Better understanding of these links could lead to compelling opportunities for interventions and work-based strategies for improving health behaviors and outcomes of employees. 
SHAME-PRONENESS, DRINKING BEHAVIORS, AND ROLE AMBIGUITY

\section{Tables}

Table 1: Participant Demographics $(n=155)$

\begin{tabular}{lll}
\hline Age & $\mathrm{N}$ & $\% *$ \\
$<21$ & 31 & $20 \%$ \\
$21-24$ & 59 & $38 \%$ \\
$25-29$ & 32 & $21 \%$ \\
$30-39$ & 23 & $15 \%$ \\
$40-49$ & 7 & $5 \%$ \\
$>50$ & 3 & $2 \%$ \\
Year at PSU & & \\
Less than 1 & & \\
$1-2$ & 56 & $36 \%$ \\
$2-4$ & 63 & $41 \%$ \\
5 or more & 29 & $19 \%$ \\
Hours worked & 7 & $5 \%$ \\
$<10$ & & \\
$10-19.9$ & & $7 \%$ \\
$20-29.9$ & 11 & $23 \%$ \\
$30-39.9$ & 36 & $38 \%$ \\
$>40$ & 59 & $21 \%$ \\
Individuals Supervised & 33 & $10 \%$ \\
0 employees & 16 & \\
$1-3$ employees & & $70 \%$ \\
$4+$ employees & & $17 \%$ \\
\hline$N=155$ & 109 &
\end{tabular}

$N=155$

*Note: may note add to $100 \%$ due to rounding 
Table 2: Study Descriptive Statistics and Correlation Matrix

\begin{tabular}{lcccccccc}
\hline & $\mathrm{M}$ & $\mathrm{SD}$ & 1 & 2 & 3 & 4 & 5 & 6 \\
\hline Trait Shame & 5.58 & 1.19 & & & & & & \\
State Shame & 0.78 & 1.07 & .03 & & & & & \\
Role Ambiguity & 1.90 & 0.80 & .01 & .08 & & & & \\
Frequency & 8.52 & 7.53 & -.12 & -.02 & .01 & & & \\
Quantity & 2.73 & 1.71 & -.07 & -.02 & -.03 & $.18^{*}$ & & \\
Age & 26.07 & 8.00 & -.03 & .01 & -.03 & $.30 * *$ & -.15 & \\
Gender & -- & -- & $.17^{* *}$ & -.01 & -.01 & .01 & -.01 & -.07 \\
\hline
\end{tabular}

Note: $* \mathrm{p}<.05, * * \mathrm{p}<.01$

$N=155$; Gender coded: $1=$ Female, $0=$ Male 
Table 3: Conditional Process Analysis for Drinking Frequency

\begin{tabular}{|c|c|c|c|c|}
\hline Predictor & $B$ & $S E$ & $t$ & $95 \% \mathrm{BC} \mathrm{CI}$ \\
\hline Mediator variable model & \multicolumn{4}{|c|}{ Outcome variable: State Shame } \\
\hline Trait Shame & -.10 & .18 & -.54 & {$[-0.45 ; 0.26]$} \\
\hline Role Ambiguity & -.11 & .49 & -.21 & {$[-1.09 ; 0.26]$} \\
\hline Gender & .28 & .21 & 1.30 & {$[-0.14 ; 0.70]$} \\
\hline Age & -.001 & .01 & -.11 & {$[-0.02 ; 0.02]$} \\
\hline Trait Shame x Role Ambiguity & .06 & .09 & .67 & {$[-0.11 ; 0.23]$} \\
\hline Dependent Variable Model & \multicolumn{4}{|c|}{ Outcome variable: Drinking Frequency } \\
\hline State Shame & -3.56 & 7.17 & 1.40 & {$[-4.12 ; 24.23]$} \\
\hline Trait Shame & -1.82 & 1.17 & -1.56 & {$[-4.12 ; 0.49]$} \\
\hline Role Ambiguity & -3.56 & 3.19 & -1.11 & {$[-9.86 ; 2.75]$} \\
\hline State Shame x Role & 1.56 & .56 & $2.78 * *$ & {$[0.45 ; 2.67]$} \\
\hline \multicolumn{5}{|l|}{ Ambiguity } \\
\hline Trait Shame x Role Ambiguity & .42 & .57 & .75 & {$[-0.70 ; 1.55]$} \\
\hline Gender & 1.41 & 1.38 & 1.01 & {$[-1.34 ; 4.16]$} \\
\hline \multirow[t]{2}{*}{ Age } & .32 & .08 & $4.30 * * *$ & {$[0.17 ; 0.47]$} \\
\hline & Effect & Boot $S E$ & & Boot $95 \% \mathrm{CI}$ \\
\hline \multicolumn{5}{|l|}{ Conditional Indirect Effect } \\
\hline State Shame (- $1 S D)$ & .06 & .19 & & {$[-0.22 ; 0.59]$} \\
\hline State Shame & -.01 & .06 & & {$[-0.19 ; 0.09]$} \\
\hline State Shame $(+1 S D)$ & .04 & .15 & & {$[-0.13 ; 0.56]$} \\
\hline
\end{tabular}

Note: $\mathrm{N}=155$. Bootstrap sample size $=5000$

$* * * p<.001, * * p<.01$ 
Table 4: Conditional Process Analysis for Drinking Quantity

\begin{tabular}{|c|c|c|c|c|}
\hline Predictor & $B$ & $S E$ & $t$ & $95 \% \mathrm{BC} \mathrm{CI}$ \\
\hline Mediator variable model & \multicolumn{4}{|c|}{ Outcome variable: State Shame } \\
\hline Trait Shame & -.10 & .18 & -.54 & {$[-0.45 ; 0.26]$} \\
\hline Role Ambiguity & -.11 & .49 & -.21 & {$[-1.09 ; 0.26]$} \\
\hline Gender & .28 & .21 & 1.30 & {$[-0.14 ; 0.70]$} \\
\hline Age & -.001 & .01 & -.11 & {$[-0.02 ; 0.02]$} \\
\hline Trait Shame x Role Ambiguity & .06 & .09 & .67 & {$[-0.11 ; 0.23]$} \\
\hline Dependent Variable Model & \multicolumn{4}{|c|}{ Outcome variable: Drinking Quantity } \\
\hline State Shame & -.64 & .32 & 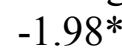 & {$[-1.27 ; 0.00]$} \\
\hline Trait Shame & -.09 & 28 & -.33 & {$[-0.65 ; 0.46]$} \\
\hline Role Ambiguity & -.32 & .77 & -.42 & {$[-1.85 ; 1.20]$} \\
\hline State Shame x Role Ambiguity & .28 & .13 & $2.07 *$ & {$[0.01 ; 0.54]$} \\
\hline Trait Shame x Role Ambiguity & -.004 & .14 & .03 & {$[-0.28 ; 0.27]$} \\
\hline Gender & .08 & .33 & .24 & {$[-0.58 ; 0.75]$} \\
\hline \multirow[t]{2}{*}{ Age } & -.032 & .02 & -1.63 & {$[-0.07 ; 0.01]$} \\
\hline & Effect & Boot $S E$ & & Boot $95 \% \mathrm{Cl}$ \\
\hline \multicolumn{5}{|l|}{ Conditional Indirect Effect } \\
\hline State Shame $(-1 S D)$ & .01 & .04 & & {$[-0.04 ; 0.12]$} \\
\hline State Shame & -.001 & .01 & & {$[-0.04 ; 0.02]$} \\
\hline State Shame $(+1 S D)$ & .01 & .03 & & {$[-0.03 ; 0.11]$} \\
\hline
\end{tabular}

Note: $\mathrm{N}=155$. Bootstrap sample size $=5000$

$* p<.05$ 
Figures:

Figure 1: Conceptual Model

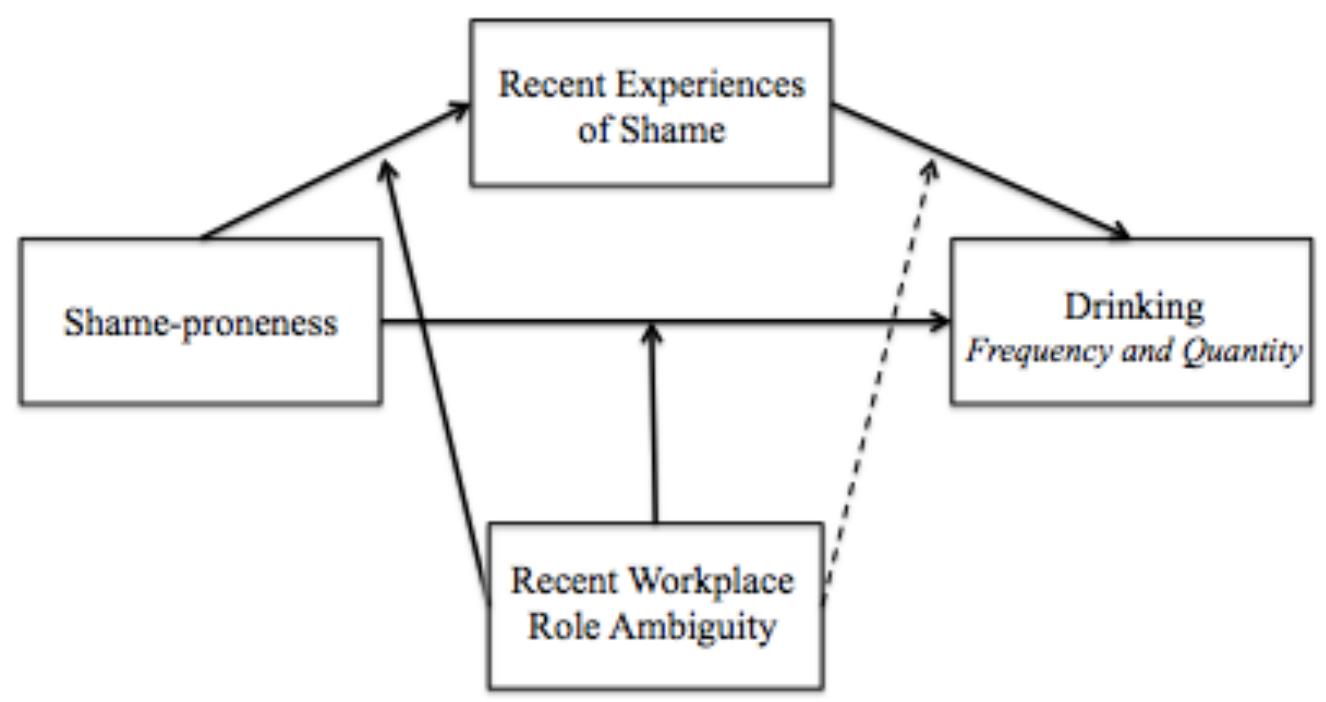


Figure 2: PROCESS Model 59 (Hayes, 2013)

Conceptual Diagram

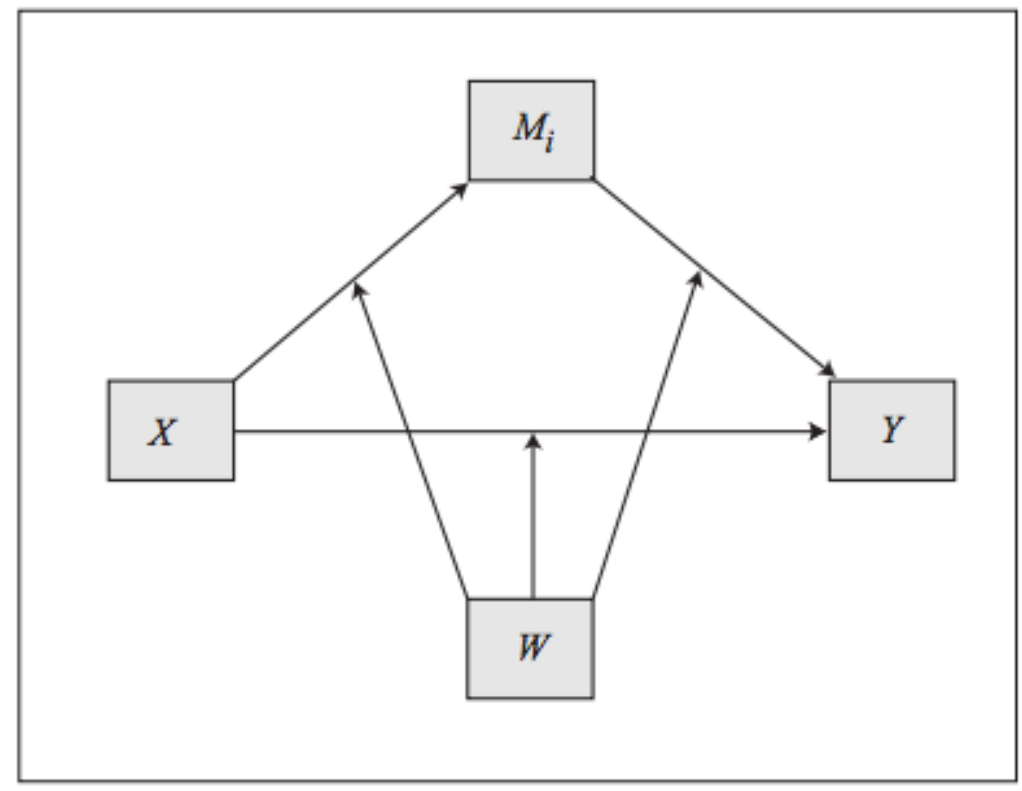

Statistical Diagram

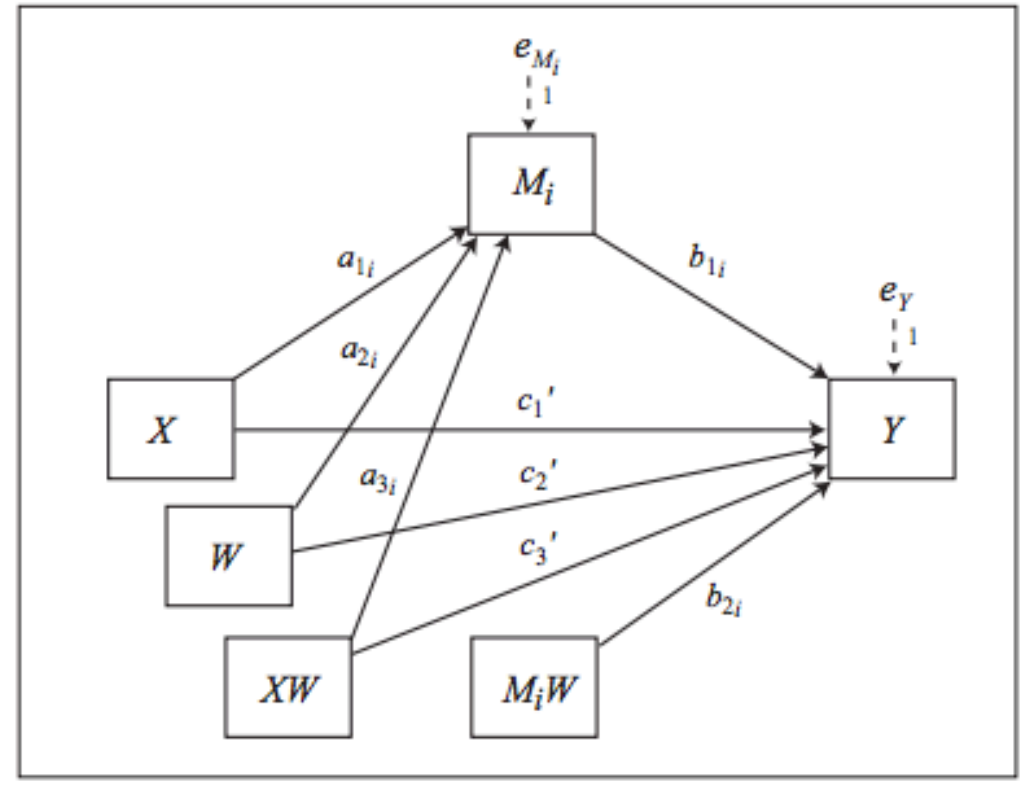

Conditional indirect effect of $X$ on $Y$ through $M_{i}=\left(a_{1 i}+a_{3 i} W\right)\left(b_{1 i}+b_{2 i} W\right)$ Conditional direct effect of $X$ on $Y=c_{1}{ }^{\prime}+c_{3}{ }^{\prime} W$ 
Figure 3: Interaction of role ambiguity and state shame on drinking frequency

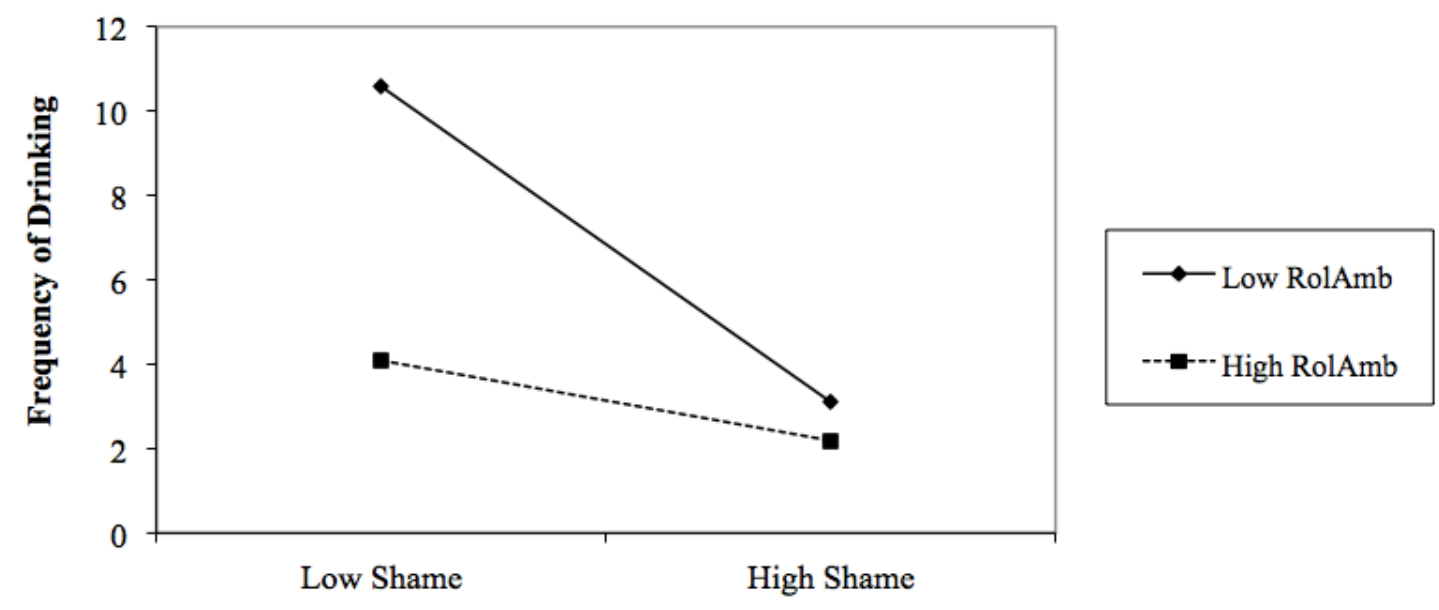


Figure 4: Interaction of role ambiguity and state shame on drinking quantity

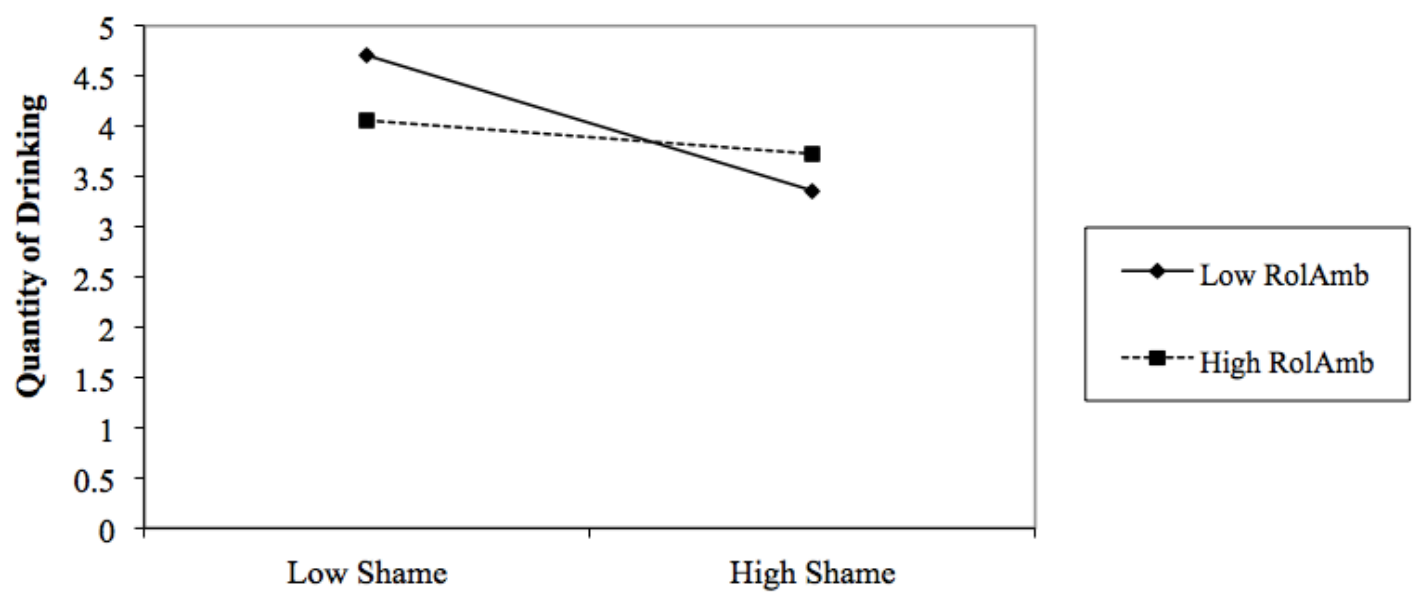


SHAME-PRONENESS, DRINKING BEHAVIORS, AND ROLE AMBIGUITY

\section{References}

Ames, G. M., Grube, J. W., \& Moore, R. S. (1997). The relationship of drinking and hangovers to workplace problems: an empirical study. Journal of studies on alcohol, 58(1), 37-47.

Armeli, S., Carney, M. A., Tennen, H., Affleck, G., \& O'Neil, T. (2000). Stress and alcohol use: A daily process examination of the stressor-vulnerability model. Journal of personality and social psychology, 78(5), 979.

Babor, T. F., \& Grant, M. (1989). From clinical research to secondary prevention: International collaboration in the development of the Alcohol Disorders Identification Test (AUDIT). Alcohol Health and Research World, 13, 371-374.

Baron, R. M., \& Kenny, D. A. (1986). The moderator-mediator variable distinction in social psychological research: Conceptual, strategic, and statistical considerations. Journal of Personality and Social Psychology, 51, 1173.

Billings, A. G., \& Moos, R. H. (1984). Coping, stress, and social resources among adults with unipolar depression. Journal of personality and social psychology, 46(4), 877.

Blatt, S. J. (1995). The destructiveness of perfectionism: Implications for the treatment of depression. American psychologist, 50(12), 1003.

Blatt, S. J., Quinlan, D. M., Pilkonis, P. A., \& Shea, M. T. (1995). Impact of perfectionism and need for approval on the brief treatment of depression: the National Institute of Mental Health Treatment of Depression Collaborative 
SHAME-PRONENESS, DRINKING BEHAVIORS, AND ROLE AMBIGUITY

Research Program revisited. Journal of Consulting and Clinical

Psychology,63(1), 125.

Blum, T. C., Roman, P. M., \& Martin, J. K. (1993). Alcohol consumption and work performance. Journal of Studies on Alcohol, 54, 61-70.

Bolger, N., DeLongis, A., Kessler, R. C., \& Schilling, E. A. (1989). Effects of daily stress on negative mood. Journal of personality and social psychology,57(5), 808.

Bouchery, E. E., Harwood, H. J., Sacks, J. J., Simon, C. J., \& Brewer, R. D. (2011). Economic costs of excessive alcohol consumption in the US, 2006.American journal of preventive medicine, 41(5), 516-524.

Burnett, S., Bird, G., Moll, J., Frith, C., \& Blakemore, S. J. (2009). Development during adolescence of the neural processing of social emotion. Journal of cognitive neuroscience, 21(9), 1736-1750.

Carlson, D. S., Kacmar, K. M., \& Williams, L. J. (2000). Construction and initial validation of a multidimensional measure of work-family conflict. Journal of Vocational behavior, 56(2), 249-276.

Carver, C. S., \& Scheier, M. F. (1978). Self-focusing effects of dispositional selfconsciousness, mirror presence, and audience presence. Journal of Personality and Social Psychology, 36(3), 324.

Chen, K., \& Kandel, D. B. (1995). The natural history of drug use from adolescence to the mid-thirties in a general population sample. American journal of public health, 85(1), 41-47.

Cohen, T. R., \& Panter, A. T. (2015). Character Traits in the Workplace: A Three-Month 
SHAME-PRONENESS, DRINKING BEHAVIORS, AND ROLE AMBIGUITY

Diary Study of Moral and Immoral Organizational Behaviors. In CB Miller, RM

Furr, A. Knobel, \& W. Fleeson.(Eds.), Character: New Directions from

Philosophy, Psychology, and Theology, 150-163.

Cohen, T. R., Wolf, S. T., Panter, A. T., \& Insko, C. A. (2011). Introducing the GASP scale: a new measure of guilt and shame proneness. Journal of personality and social psychology, 100(5), 947.

Conger, J. J. (1956). Reinforcement theory and the dynamics of alcoholism. Quarterly journal of studies on alcohol.

Conigrave, K. M., Hall, W. D., \& Saunders, J. B. (1995). The AUDIT questionnaire: choosing a cut-off score. Addiction, 90(10), 1349-1356.

Cooper, C. L., Mallinger, M., \& Kahn, R. (1978). Identifying sources of occupational stress among dentists. Journal of Occupational Psychology,51(3), 227-234.

Cooper, M. L. (1994). Motivations for alcohol use among adolescents: Development and validation of a four-factor model. Psychological assessment, 6(2), 117.

Cooper, M. L., Frone, M. R., Russell, M., \& Mudar, P. (1995). Drinking to regulate positive and negative emotions: a motivational model of alcohol use. Journal of personality and social psychology, 69(5), 990.

Cooper, M. L., Russell, M., Skinner, J. B., \& Windle, M. (1992). Development and validation of a three-dimensional measure of drinking motives. Psychological assessment, 4(2), 123.

Cooper, M. L., Russell, M., Skinner, J. B., Frone, M. R., \& Mudar, P. (1992). Stress and 
SHAME-PRONENESS, DRINKING BEHAVIORS, AND ROLE AMBIGUITY

alcohol use: moderating effects of gender, coping, and alcohol expectancies. Journal of abnormal psychology, 101(1), 139.

Cotton, S. J., Dollard, M. F., \& De Jonge, J. (2002). Stress and student job design: Satisfaction, well-being, and performance in university students. International Journal of Stress Management, 9(3), 147-162.

Cox, W. M., \& Klinger, E. (1988). A motivational model of alcohol use. Journal of abnormal psychology, 97(2), 168.

Cranford, J. A., Shrout, P. E., Iida, M., Rafaeli, E., Yip, T., \& Bolger, N. (2006). A procedure for evaluating sensitivity to within-person change: can mood measures in diary studies detect change reliably?. Personality and Social Psychology Bulletin, 32(7), 917-929.

Cunradi, C. B., Greiner, B. A., Ragland, D. R., \& Fisher, J. (2005). Alcohol, stressrelated factors, and short-term absenteeism among urban transit operators. Journal of urban health, 82(1), 43-57.

Davis, D., \& Brock, T. C. (1975). Use of first person pronouns as a function of increased objective self-awareness and performance feedback. Journal of Experimental Social Psychology, 11(4), 381-388.

Dawson, D. A., Grant, B. F., Stinson, F. S., Chou, P. S., Huang, B., \& Ruan, W. (2005). Recovery from DSM-IV alcohol dependence: United States, 2001-2002. Addiction, 100(3), 281-292.

Dearing, R. L., Stuewig, J., \& Tangney, J. P. (2005). On the importance of distinguishing 
SHAME-PRONENESS, DRINKING BEHAVIORS, AND ROLE AMBIGUITY

shame from guilt: Relations to problematic alcohol and drug use. Addictive behaviors, 30(7), 1392-1404.

El Leithy, S., Brown, G. P., \& Robbins, I. (2006). Counterfactual thinking and posttraumatic stress reactions. Journal of abnormal psychology, 115(3), 629.

Fischer, K. W., \& Tangney, J. P. (Eds.). (1995). Self-conscious emotions: The psychology of shame, guilt, embarrassment, and pride. Guilford Press.

Fisher, C. D., \& Gitelson, R. (1983). A meta-analysis of the correlates of role conflict and ambiguity. Journal of applied psychology, 68(2), 320.

Fossum, M. A., \& Mason, M. J. (1989). Facing shame: Families in recovery. WW Norton \& Company.

Frone, M. R. (1999). Work stress and alcohol use. Alcohol Research and Health, 23, 284291.

Frone, M. R. (2003). Predictors of overall and on-the-job substance use among young workers. Journal of Occupational Health Psychology, 8, 39.

Frone, M. R. (2008). Are work stressors related to employee substance use? The importance of temporal context assessments of alcohol and illicit drug use. Journal of Applied Psychology, 93, 199.

Frone, M. R. (2015). Relations of negative and positive work experiences to employee alcohol use: Testing the intervening role of negative and positive work rumination. Journal of Occupational Health Psychology, 20, 148.

Greeley, J., \& Oei, T. (1999). Alcohol and tension reduction. Psychological theories of drinking and alcoholism, 2, 14-53. 
Hammer, L. B., Grigsby, T. D., \& Woods, S. (1998). The conflicting demands of work, family, and school among students at an urban university. The journal of Psychology, 132(2), 220-226.

Harris, C. R., \& Darby, R. S. (2009). Shame in physician-patient interactions: Patient perspectives. Basic and Applied Social Psychology, 31(4), 325-334.

Hawthorne, N. (1984). The scarlet letter. Pleasantville, N.Y: Reader's Digest Association.

Hayes, A. F. (2013). Introduction to mediation, moderation, and conditional process analysis: A regression-based approach. New York,NY: The Guilford Press.

Holloway, E A. (1994). Low-dose alcohol effects on human performance: A review of post-1984 research (Office of Aviation Medicine Report No. DOT/FAA/AM94/24). Washington, DC: Federal Aviation Administration.

Hull, J. G. (1981). A self-awareness model of the causes and effects of alcohol consumption. Journal of Abnormal Psychology, 90(6), 586.

Hull, J. G., Levenson, R. W., Young, R. D., \& Sher, K. J. (1983). Self-awarenessreducing effects of alcohol consumption. Journal of Personality and Social Psychology, 44(3), 461.

Johnson, D.E. (2012). Considering Shame and Its Implications for Student Learning. College student journal (0146-3934), 46 (1), p. 3.

Kahn, R. L., Wolfe, D. M., Quinn, R. P., Snoek, J. D., \& Rosenthal, R. A. (1964). Organizational stress: Studies in role conflict and ambiguity.

Leith, K. P., \& Baumeister, R. F. (1998). Empathy, shame, guilt, and narratives of 
SHAME-PRONENESS, DRINKING BEHAVIORS, AND ROLE AMBIGUITY

interpersonal conflicts: guilt-prone people are better at perspective taking. Journal of personality, 66(1), 1-37.

Lewis, H. B. (1971). Shame and guilt in neurosis. Psychoanalytic review, 58(3), 419.

Maisto, S. A., Carey, K. B., \& Bradizza, C. M. (1999). Social Learning Theory. Psychological theories of drinking and alcoholism, 106.

Mangione, T. W., Howland, J., Amick, B., Cote, J., Lee, M., Bell, N., \& Levine, S. (1999). Employee drinking practices and work performance. Journal of studies on alcohol, 60(2), 261-270.

Manning, M. R., Ismail, A. M., \& Sherwood, J. J. (1981). Effects of role conflict on selected physiological affective, and performance variables: A laboratory simulation. Multivariable Behavioral Research, 16, 125-141.

Matano, R. A., Wanat, S. F., Westrup, D., Koopman, C., \& Whitsell, S. D. (2002). Prevalence of alcohol and drug use in a highly educated workforce. The journal of behavioral health services \& research, 29(1), 30-44.

McGrath, J. E. (1976). Stress and behavior in organizations. Handbook of industrial and organizational psychology, 1351, 1396.

Meehan, W., O'Connor, L. E., Berry, J. W., Weiss, J., \& Acampora, A. (1996). Guilt, shame, and depression in clients in recovery from addiction. Journal of psychoactive drugs, 28(2), 125-134.

Mertler, C. \& Vannatta, R.A. (2005). Advanced and Multivariate Statistical Methods. (pp. 31-32). Pyrczak Publishing; California.

Mohr, C. D., Brannan, D., Mohr, J., Armeli, S., \& Tennen, H. (2008). Evidence for 
SHAME-PRONENESS, DRINKING BEHAVIORS, AND ROLE AMBIGUITY

positive mood buffering among college student drinkers. Personality and Social Psychology Bulletin, 34(9), 1249-1259.

Mohr, C.D., Armeli, S., Tennen, H., \& Todd, M. (2010). The complexities of modeling mood-drinking relationships: Lessons learned from daily process research (pp. 189-216). In J. Kassel (Ed.), Substance Abuse and Emotion. Washington, D.C.: American Psychological Association.

Mohr, C.D., Arpin, S.N., McCabe, C.T, \& Haverly, S.N. (2016). Capitalization and Alcohol Use: A moderated mediation model of relationship status, capitalization, drinking motives and alcohol consumption. Journal of Social and Clinical Psychology.35(4), 301.

Mullahy, J., \& Sindelar, J. L. (1998). Drinking, problem drinking, and productivity. In Recent developments in alcoholism (pp. 347-359). Springer US.

National Institute on Alcohol Abuse and Alcoholism (2004). NIAAA Council Approves Definition of Binge Drinking. NIAAA Newsletter. Retrieved from: http://pubs.niaaa.nih.gov/publications/Newsletter/winter2004/Newsletter_N umber3.pdf

Niedenthal, P. M., Tangney, J. P., \& Gavanski, I. (1994). " If only I weren't" versus" If only I hadn't": Distinguishing shame and guilt in conterfactual thinking. Journal of personality and social psychology, 67(4), 585.

O'Connor, L. E., Berry, J. W., Inaba, D., Weiss, J., \& Morrison, A. (1994). Shame, guilt, and depression in men and women in recovery from addiction. Journal of substance abuse treatment, 11(6), 503-510. 
Park, C. L., \& Levenson, M. R. (2002). Drinking to cope among college students: prevalence, problems and coping processes. Journal of studies on alcohol, 63(4), 486-497.

Planty, M., Hussar, W., Snyder, T., Kena, G., KewalRamani, A., Kemp, J., Bianco, K., Dinkes, R. (2009). The Condition of Education 2009 (NCES 2009-081). National Center for Education Statistics, Institute of Education Sciences, U.S. Department of Education. Washington, DC.

Preacher, K. J., Rucker, D. D., \& Hayes, A. F. (2007). Addressing Moderated Mediation Hypotheses: Theory, Methods, and Prescriptions. Multivariate Behavioral Research, 42(1), 185-227.

Randles, D., \& Tracy, J. L. (2013). Nonverbal displays of shame predict relapse and declining health in recovering alcoholics. Clinical Psychological Science, 1(2), 149-155.

Richardson, K. M., \& Rothstein, H. R. (2008). Effects of occupational stress management intervention programs: a meta-analysis. Journal of occupational health psychology, 13(1), 69.

Rizzo, J. R., House, R. J., \& Lirtzman, S. I. (1970). Role conflict and ambiguity in complex organizations. Administrative science quarterly, 150-163.

Sarbin, T. R., \& Allen, V. L. (1968). Role theory.

Sayette, M. A. (2000). Does drinking reduce stress? Alcohol Research \& Health, 23, 250255.

Schaufeli, W. B., Martinez, I. M., Pinto, A. M., Salanova, M., \& Bakker, A. B. (2002). 
SHAME-PRONENESS, DRINKING BEHAVIORS, AND ROLE AMBIGUITY

Burnout and engagement in university students a cross-national study. Journal of cross-cultural psychology, 33(5), 464-481.

Shenkar, O., \& Zeira, Y. (1992). Role conflict and role ambiguity of chief executive officers in international joint ventures. Journal of international business studies, $55-75$.

Sher, K. J., Bartholow, B. D., Peuser, K., Erickson, D. J., \& Wood, M. D. (2007). Stressresponse-dampening effects of alcohol: Attention as a mediator and moderator. Journal of Abnormal Psychology, 116(2), 362.

Slutske, W. S., Hunt-Carter, E. E., Nabors-Oberg, R. E., Sher, K. J., Bucholz, K. K., Madden, P. A., ... \& Heath, A. C. (2004). Do college students drink more than their non-college-attending peers? Evidence from a population-based longitudinal female twin study. Journal of abnormal psychology,113(4), 530.

Snyder, M., \& Ickes, W. (1985). Personality and social behavior. Handbook of social psychology, 2, 883-947.

Tabachnick, B.G., \& Fidell, L.S. (2007). Using Multivariate Statistics, $5^{\text {th }}$ ed. Boston: Pearson.

Talbot, J. A., Talbot, N. L., \& Tu, X. (2004). Shame-proneness as a diathesis for dissociation in women with histories of childhood sexual abuse. Journal of Traumatic Stress, 17(5), 445-448.

Tangney, J. P. (1992). Situational determinants of shame and guilt in young adulthood. Personality and Social Psychology Bulletin, 18(2), 199-206.

Tangney, J. P. (1994). The mixed legacy of the superego: Adaptive and maladaptive 
SHAME-PRONENESS, DRINKING BEHAVIORS, AND ROLE AMBIGUITY

aspects of shame and guilt.

Tangney, J. P. (1995). Recent advances in the empirical study of shame and guilt. The American Behavioral Scientist, 38(8), 1132.

Tangney, J. P. (1996). Conceptual and methodological issues in the assessment of shame and guilt. Behaviour research and therapy, 34(9), 741-754.

Tangney, J. P., \& Dearing, R. L. (2002). Emotions and social behavior. Shame and guilt. New York: Guilford Press, 10(9781412950664), n388.

Tangney, J. P., \& Dearing, R. L. (2003). Shame and guilt. Guilford Press.

Tangney, J. P., Dearing, R. L., Wagner, P. E., \& Gramzow, R. (2000). The Test of SelfConscious Affect-3 (TOSCA-3). Fairfax, VA: George Mason University.

Tangney, J. P., Miller, R. S., Flicker, L., \& Barlow, D. H. (1996). Are shame, guilt, and embarrassment distinct emotions?. Journal of personality and social psychology, 70(6), 1256.

Tangney, J. P., Stuewig, J., \& Martinez, A. G. (2014). Two faces of shame the roles of shame and guilt in predicting recidivism. Psychological science,25(3), 799-805.

Tracy, J. L., \& Robins, R. W. (2004). " Putting the Self Into Self-Conscious Emotions: A Theoretical Model". Psychological Inquiry, 15(2), 103-125.

Treeby, M., \& Bruno, R. (2012). Shame and guilt-proneness: Divergent implications for problematic alcohol use and drinking to cope with anxiety and depression symptomatology. Personality and Individual Differences, 53(5), 613-617.

Turner, J. C., Oakes, P. J., Haslam, S. A., \& McGarty, C. (1994). Self and collective: 
SHAME-PRONENESS, DRINKING BEHAVIORS, AND ROLE AMBIGUITY

Cognition and social context. Personality and social psychology bulletin, 20, 454454.

U.S. Department of Health and Human Services and U.S. Department of Agriculture. 2015 - 2020 Dietary Guidelines for Americans. $8^{\text {th }}$ Edition.

December 2015. Available athttp://health.gov/dietaryguidelines/2015/guidelines/.

Van Sell, M., Brief, A. P., \& Schuler, R. S. (1981). Role conflict and role ambiguity: Integration of the literature and directions for future research. Human relations, 34(1), 43-71.

Watson, D., Clark, L. A., \& Tellegen, A. (1988). Development and validation of brief measures of positive and negative affect: the PANAS scales. Journal of personality and social psychology, 54(6), 1063.

Wechsler, H., \& Nelson, T. F. (2001). Binge drinking and the American college students: What's five drinks?. Psychology of Addictive Behaviors, 15(4), 287.

West, J. A., \& Sutker, P. B. (1990). Alcohol consumption, tension reduction, and mood enhancement. Why people drink: Parameters of alcohol as a reinforcer, 93-130.

Wills, T. A., \& Shiffman, S. (1985). Coping and substance use: A conceptual framework. Coping and substance use, 3-24.

Wilsnack, R. W., Wilsnack, S. C., Kristjanson, A. F., Vogeltanz-Holm, N. D., \& Gmel, G. (2009). Gender and alcohol consumption: patterns from the multinational GENACIS project. Addiction, 104(9), 1487-1500.

Woien, S. L., Ernst, H. A., Patock-Peckham, J. A., \& Nagoshi, C. T. (2003). Validation 
of the TOSCA to measure shame and guilt. Personality and Individual Differences, 35(2), 313-326.

Yun, S., Takeuchi, R., \& Liu, W. (2007). Employee self-enhancement motives and job performance behaviors: investigating the moderating effects of employee role ambiguity and managerial perceptions of employee commitment. Journal of Applied Psychology, 92(3), 745. 


\title{
Appendix A: Guilt and Shame-Proneness Scale
}

\author{
GASP: Guilt and Shame-Proneness Scale \\ (Cohen, Wolf, Panter, and Insko, 2011)
}

Instructions: In this questionnaire you will read about situations that people are likely to encounter in day-to-day life, followed by common reactions to those situations. As you read each scenario, try to imagine yourself in that situation. Then indicate the likelihood that you would react in the way described.

\begin{tabular}{ccccccc}
\hline 1 & 2 & 3 & 4 & 5 & 6 & 7 \\
Very & Unlikely & Slightly & About 50\% & Slightly & Likely & Very \\
Unlikely & & Unlikely & Likely & Likely & & Likely \\
\hline
\end{tabular}

1. After realizing you have received too much change at a store, you decide to keep it because the salesclerk doesn't notice. What is the likelihood that you would feel uncomfortable about keeping the money?

2. You are privately informed that you are the only one in your group that did not make the honor society because you skipped too many days of school. What is the likelihood that this would head you to become more responsible about attending school?

3. You rip an article out of a journal in the library and take it with you. Your teacher discovers what you did and tells the librarian and your entire class. What is the likelihood that this would make you feel like a bad person? 4. After making a big mistake on an important project at work in which people were depending on you, your boss criticizes you in front of your coworkers. What is the likelihood that you would feign sickness and leave work? 5. You receal a friend's secret, though your friend never finds out. What is the likelihood that your failure to keep the secret would lead you to exert extra effort to keep secrets in the future?

6. You give a bad presentation at work. Afterwards your boss tells your coworkers it was your fault that your company lost the contract. What is the likelihood that you would feel incompetent?

7. A friend tells you that you boast a great deal. What is the likelihood that you would stop spending time with that friend?

8. Your home is very messy and unexpected guests knocks on your door and invites themselves in. What is the likelihood that you would avoid the guests until they leave?

9. You secretly commit a felony. What is the likelihood that you would feel remorse about breaking the law?

10. You successfully exaggerate your damages in a lawsuit. Months later, your lies are discovered and you are charged with perjury. What is the likelihood that you would think you are a despicable human being?

11. You strongly defend a point of view in a discussion, and though nobody was aware of it, you realize you were wrong. What is the likelihood that this would make you think more carefully before you speak? 
12. You take office supplies from home for personal use and are caught by your boss. What is the likelihood that this would lead you to quit your job?

13. You make a mistake at work and find out a coworker is blamed for the error. Later, your coworker confronts you about your mistake. What is the likelihood that you would feel like a coward?

14. At a coworker's housewarming party, you spill red wine on their new cream-colored carpet. You cover the stain with a chair so that nobody notices your mess. What is the likelihood that you would feel that the way you acted was pathetic?

15. While discussing a heated subject with friends, you suddenly realize you are shouting though nobody seems to notice. What is the likelihood that you would try to act more considerately toward your friends?

16. You like to people but they never find out about it. What is the likelihood that you would feel terrible about the lies you told?

GASP Scoring: The GASP is scored by averaging the four items in each subscale.

Guilt-Negative-Behavior-Evaluation (NBE): 1, 9, 14, 16

Guilt-Repair: 2, 5, 11, 15

Shame-Negative-Self-Evaluation (NSE): 3, 6, 10, 13

Shame-Withdraw: 4, 7, 8, 12 


\title{
Appendix B: Role Ambiguity Scale
}

\author{
Role Ambiguity Scale \\ (Rizzo, House, \& Lirtzman, 1970)
}

Instructions: Still thinking about the job where you work the most hours, please read each statement carefully and rate the extent to which you agree with each statement over the past 30 days based on the scale below.

\begin{tabular}{ccccc}
\hline 1 & 2 & 3 & 4 & 5 \\
Strongly Disagree & Disagree & $\begin{array}{c}\text { Neither agree nor } \\
\text { disagree }\end{array}$ & Agree & Strongly Agree \\
\hline
\end{tabular}

1. I know exactly what is expected of me.

2. I know that I have divided my time properly.

3. Explanation is clear of what has to be done.

4. I feel certain about how much authority I have.

5. I know what my responsibilities are.

6. Clear, planned goals and objectives exist for my job 